ARTICLE

\title{
Engineering active sites on hierarchical transition bimetal oxides/sulfides heterostructure array enabling robust overall water splitting
}

Panlong Zhai ${ }^{1,5}$, Yanxue Zhang ${ }^{2,5}$, Yunzhen Wu ${ }^{1,5}$, Junfeng $\mathrm{Gao}^{2}$, Bo Zhang ${ }^{1}$, Shuyan Cao ${ }^{1}$, Yanting Zhang ${ }^{1}$, Zhuwei $\mathrm{Li}^{1}$, Licheng Sun (1) ${ }^{1,3,4} \&$ Jungang Hou ${ }^{1 \times}$

Rational design of the catalysts is impressive for sustainable energy conversion. However, there is a grand challenge to engineer active sites at the interface. Herein, hierarchical transition bimetal oxides/sulfides heterostructure arrays interacting two-dimensional $\mathrm{MoO}_{x} /$ $\mathrm{MoS}_{2}$ nanosheets attached to one-dimensional $\mathrm{NiO}_{x} / \mathrm{Ni}_{3} \mathrm{~S}_{2}$ nanorods were fabricated by oxidation/hydrogenation-induced surface reconfiguration strategy. The $\mathrm{NiMoO}_{x} / \mathrm{NiMoS}$ heterostructure array exhibits the overpotentials of $38 \mathrm{mV}$ for hydrogen evolution and 186 $\mathrm{mV}$ for oxygen evolution at $10 \mathrm{~mA} \mathrm{~cm}{ }^{-2}$, even surviving at a large current density of $500 \mathrm{~mA}$ $\mathrm{cm}^{-2}$ with long-term stability. Due to optimized adsorption energies and accelerated water splitting kinetics by theory calculations, the assembled two-electrode cell delivers the industrially relevant current densities of 500 and $1000 \mathrm{~mA} \mathrm{~cm}^{-2}$ at record low cell voltages of 1.60 and $1.66 \mathrm{~V}$ with excellent durability. This research provides a promising avenue to enhance the electrocatalytic performance of the catalysts by engineering interfacial active sites toward large-scale water splitting.

\footnotetext{
${ }^{1}$ State Key Laboratory of Fine Chemicals, School of Chemical Engineering, Dalian University of Technology, 116024 Dalian, P. R. China. ${ }^{2}$ Laboratory of Materials Modification by Laser, Ion and Electron Beams, Dalian University of Technology, Ministry of Education, 116024 Dalian, P. R. China. ${ }^{3}$ College of Science, Westlake University, 310024 Hangzhou, P. R. China. ${ }^{4}$ Department of Chemistry, School of Engineering Sciences in Chemistry, Biotechnology and Health, KTH Royal Institute of Technology, 10044 Stockholm, Sweden. ${ }^{5}$ These authors contributed equally: Panlong Zhai, Yanxue Zhang, Yunzhen Wu.

$凶_{\text {email: jhou@dlut.edu.cn }}$
} 
T he generation of clean energy from water electrolysis is a feasible solution to overcome the problems of energy issues ${ }^{1}$. The sustainable alternative for hydrogen generation is electrocatalytic water splitting, involving hydrogen evolution reaction (HER) and oxygen evolution reaction $(\mathrm{OER})^{2}$. Generally, noble materials, Pt for HER and $\mathrm{RuO}_{2}$ or $\mathrm{IrO}_{2}$ for OER, are typical electrocatalysts. Nevertheless, the practical application is limited by the use of noble materials owing to the scarcity and the high cost. To this end, it is interesting to produce bifunctional materials by the integration of OER and HER catalysts towards water splitting in various media ${ }^{3}$. To address the challenges, catalyzing HER, OER and overall water splitting have been conducted by extensive catalysts, such as oxides, hydroxides, phosphides, nitrides and chalcogenides ${ }^{4-11}$. Thus, it is urgently needed to design earth-abundant and low-cost non-noble-metal catalysts for industrial applications.

Among various materials, Mo- and Ni-based sulfides are promising transition-metal electrocatalysts. To improve the performance of these catalysts, various strategies, such as morphology engineering, defect engineering, and heterostructure engineering have been adopted in this field. Architectural nanostructures have been controlled by the synthesis regulation of the electrocatalysts owe to inherent anisotropy and high flexibility ${ }^{5-8}$. Inspired by the advantages of the architectures, the integration of different nanostructures can effectively optimize the electrocatalytic performance. For example, $\mathrm{MoO}_{3}$ nanodots supported on $\mathrm{MoS}_{2}$ monolayer, $\mathrm{MoNi}_{4}$ anchored $\mathrm{MoO}_{2}$ cuboids or $\mathrm{MoO}_{3-\mathrm{x}}$ nanorods and $\mathrm{NiS}_{2} / \mathrm{N}-\mathrm{NiMoO}_{4}$ nanosheets/nanowires have been produced for the excellent electrocatalytic water splitting ${ }^{12-15}$, providing an appealing platform with the hierarchical nanostructures. Apart from morphology engineering, the hybrids can be extensively constructed by use of different transition-metal electrocatalysts through heterostructure engineering, regulating electron transfer and active site as well as the activity owe to the construction of coupling interfaces and the synergistic effect of the heterostructures. For instance, a large number of the heterostructures, such as $\mathrm{NiMo} / \mathrm{NiMoO}_{x}^{8}, \mathrm{Co}_{3} \mathrm{O}_{4} / \mathrm{Fe}_{0.33} \mathrm{Co}_{0.66} \mathrm{P}^{16}, \mathrm{Ni}_{2} \mathrm{P} / \mathrm{NiP}_{2}{ }^{17}$, $\mathrm{NiFe}(\mathrm{OH})_{x} / \mathrm{FeS}^{18}, \mathrm{Pt}_{2} \mathrm{~W} / \mathrm{WO}_{3}{ }^{19}, \mathrm{CuCo} / \mathrm{CuCoO}_{x}{ }^{20}, \mathrm{Co}(\mathrm{OH})_{2} /$ $\mathrm{PANI}^{21}, \mathrm{FeOOH} / \mathrm{Co} / \mathrm{FeOOH}^{22}, \mathrm{Co}_{0.85} \mathrm{Se} / \mathrm{NiFe} /$ graphene $^{23}, \mathrm{Ni}_{3} \mathrm{~N} /$ $\mathrm{VN}^{24}, \mathrm{NiCu}-\mathrm{NiCuN}^{25}$, have been extensively synthesized for the enhanced electrochemical activities. Typically, sulfides-based heterostructures, such as CoS-doped $\beta-\mathrm{Co}(\mathrm{OH})_{2} / \mathrm{MoS}_{2+x}{ }^{26}$, $\mathrm{MoS}_{2} / \mathrm{Fe}_{5} \mathrm{Ni}_{4} \mathrm{~S}_{8}{ }^{27}, \quad \mathrm{MoS}_{2} / \mathrm{Ni}_{3} \mathrm{~S}_{2}{ }^{28}, \quad \mathrm{NiS}_{2} / \mathrm{MoS}_{2}{ }^{29}, \quad \mathrm{MoS}_{2} / \mathrm{Co}_{9} \mathrm{~S}_{8} /$ $\mathrm{Ni}_{3} \mathrm{~S}_{2} / \mathrm{Ni}^{30}$, and $\mathrm{MoS}_{2} /(\mathrm{Co}, \mathrm{Fe}, \mathrm{Ni})_{9} \mathrm{~S}_{8}$ coupled FeCoNi-based arrays ${ }^{31}$, have been systematically explored for the improved activities of electrochemical water splitting. With regard to transition-metal dichalcogenides, $\mathrm{MoS}_{2}$ and $\mathrm{Ni}_{3} \mathrm{~S}_{2}$ materials have been substantially explored as HER electrocatalysts ${ }^{32-35}$. However, the HER performance of transition metal sulfides is limited by poor charge transport, low active site reactivity, and inefficient electrical contact with the supported catalysts ${ }^{36}$. Especially, the generation of $\mathrm{S}-\mathrm{H}_{\mathrm{ads}}$ bonds ( $\mathrm{H}$ atoms adsorption, $\mathrm{H}_{\mathrm{ads}}$ ) on the surface of metal sulfides is beneficial for $\mathrm{H}$ adsorption, while it is difficult to conduct the conversion of the $\mathrm{H}_{\text {ads }}$ to $\mathrm{H}_{2}{ }^{36,37}$. However, the OER performance of metal sulfides remains far from satisfactory ${ }^{27-31}$. Owe to long-time durability as major obstacle, there is less report about the electrocatalysts, delivering large catalytic current densities (e.g., 500 and $1000 \mathrm{~mA} \mathrm{~cm}^{-2}$ ) for practical application ${ }^{38-41}$. Based on the above-mentioned analysis, it is essential to design the rational heterostructures through the combined regulation of architectural morphology and heterostructures, engineering active sites, optimizing energy adsorption, and accelerating water splitting kinetics towards large-scale electrolysis.

Herein, three-dimensional (3D) $\mathrm{NiMoO}_{x} / \mathrm{NiMoS}$ heterostructure array is fabricated by surface reconfiguration strategy through oxygen plasma as oxidation treatment and subsequent hydrogenation regulation by use of NiMoS architecture as the precursor, interacting two-dimensional (2D) $\mathrm{MoO}_{x} / \mathrm{MoS}_{2}$ nanosheets attached to one-dimensional (1D) $\mathrm{NiO}_{x} / \mathrm{Ni}_{3} \mathrm{~S}_{2}$ nanorods array. As-synthesized $\mathrm{NiMoO}_{x} / \mathrm{NiMoS}$ array presents the remarkable electrocatalytic performance, achieving the low overpotentials of $38,89,174$, and $236 \mathrm{mV}$ for HER and 186, 225, 278 , and $334 \mathrm{mV}$ for OER at $10,100,500$, and $1000 \mathrm{~mA} \mathrm{~cm}^{-2}$, even surviving at large current densities of 100 and $500 \mathrm{~mA} \mathrm{~cm}^{-2}$ with long-term stability. The remarkable electrocatalytic performance of transition bimetal oxides/sulfides heterostructure array as the industrially promising electrocatalyst is ascribed to not only the simultaneous modulation of component and geometric structure, but also the systematic optimization of charge transfer, abundant electrocatalytic active sites, and exceptionally synergistic effect of the heterostructure interfaces. The turnover frequency (TOF) of $\mathrm{NiMoO}_{x} / \mathrm{NiMoS}$ array at the overpotential of $100 \mathrm{mV}$ is $\sim 45$ times higher than that of NiMoS array. Density functional theory calculations reveal that the coupling interface between $\mathrm{NiMoO}_{x}$ and NiMoS optimizes adsorption energies and accelerates water splitting kinetics, thus promoting the electrocatalytic performance. Especially, the assembled two-electrode cell by use of $\mathrm{NiMoO}_{x} / \mathrm{NiMoS}$ array delivers the industrially required current densities of 500 and $1000 \mathrm{~mA} \mathrm{~cm}^{-2}$ at the low cell voltages of 1.60 and $1.66 \mathrm{~V}$, along with excellent durability, thus holding great promise for industrial water splitting application.

\section{Results}

Synthesis and characterization. The hierarchical $\mathrm{NiMoO}_{x} /$ NiMoS array was fabricated by oxidation/hydrogenation-induced surface reconfiguration strategy by use of NiMoS precursor, assembling as two-electrode cell towards industrially electrocatalytic water splitting (Fig. 1 and Supplementary Fig. 1). To determine the crystal structure, X-ray diffraction (XRD) patterns of NiMoS-based arrays are showed (Supplementary Fig. 2). Based on the hydrothermal reaction, the representative peaks of the precursors can be assigned to the planes of $\mathrm{MoS}_{2}$ phase (JCPDS No. 37-1492) and $\mathrm{Ni}_{3} \mathrm{~S}_{2}$ phase (JCPDS No. 44-1418), confirming the formation of individual $\mathrm{MoS}_{2}$ and $\mathrm{Ni}_{3} \mathrm{~S}_{2}$ as well as $\mathrm{MoS}_{2} /$ $\mathrm{Ni}_{3} \mathrm{~S}_{2}$ heterostructure as the precursors (Supplementary Fig. 2a). After oxygen plasma as oxidation treatment and subsequent hydrogenation regulation, several $\mathrm{MoO}_{3}$ (JCPDS No.47-1320), $\mathrm{MoO}_{2}$ (JCPDS No. 50-0739), and $\mathrm{NiO}$ (JCPDS No.44-1159) phases as well as the mixed $\mathrm{MoO}_{3} / \mathrm{MoO}_{2} / \mathrm{NiO} / \mathrm{Ni}$ phases are observed in $\mathrm{MoS}_{2}, \mathrm{Ni}_{3} \mathrm{~S}_{2}$, and $\mathrm{MoS}_{2} / \mathrm{Ni}_{3} \mathrm{~S}_{2}$ (Supplementary Fig. 2b). Thus, all above-mentioned results demonstrate the successful formation of $\mathrm{NiO}_{\mathrm{x}} / \mathrm{Ni}_{3} \mathrm{~S}_{2}, \mathrm{MoO}_{x} / \mathrm{MoS}_{2}$, and $\mathrm{NiMoO}_{x} /$ $\mathrm{NiMoS}$ heterostructure arrays.

To confirm the geometric morphologies of individual arrays by scanning electron microscope (SEM), as shown in Fig. 2a, d, $\mathrm{MoS}_{2}$ nanosheets as the precursor with an average size over $1 \mu \mathrm{m}$ are homogeneously supported on the conductive substrate. While the rough surface of $\mathrm{Ni}_{3} \mathrm{~S}_{2}$ array as the precursor is observed (Supplementary Fig. 3). Interestingly, two-dimensional (2D) $\mathrm{MoS}_{2}$ nanosheets with an average size below $1 \mu \mathrm{m}$ are attached to one-dimensional (1D) $\mathrm{Ni}_{3} \mathrm{~S}_{2}$ nanorods array on 3D foam substrate, resulting into the formation of hierarchical $\mathrm{MoS}_{2} / \mathrm{Ni}_{3} \mathrm{~S}_{2}$ (denoted as NiMoS) heterostructure array (Fig. 2b, e). After the oxidation/hydrogenation treatment of NiMoS array, there is no obvious change upon the main morphology for $3 \mathrm{D} \mathrm{NiMoO}_{x} /$ NiMoS heterostructure array. However, the small size and rough surface of $\mathrm{MoS}_{2}$ nanosheets in $\mathrm{NiMoO}_{x} / \mathrm{NiMoS}$ array are observed in comparison of $\mathrm{MoS}_{2}$ in NiMoS array (Fig. 2cf). Meanwhile, the energy-dispersive X-ray (EDX) spectra and 


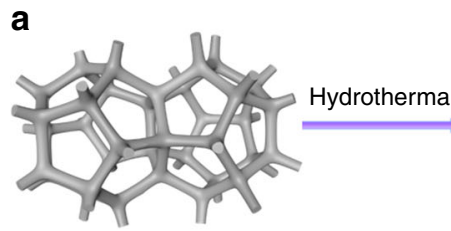

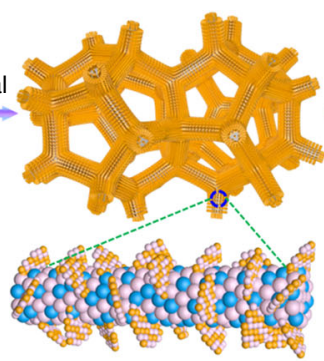

NiMos precursor

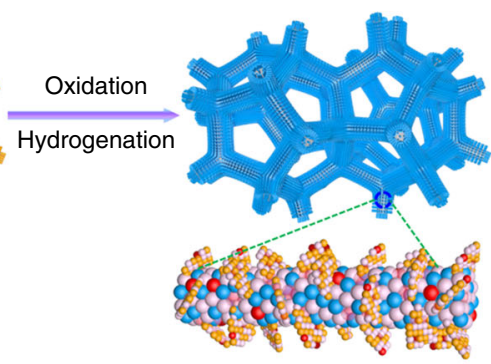

NiMoO$/{ }_{x}$ NiMos array

b

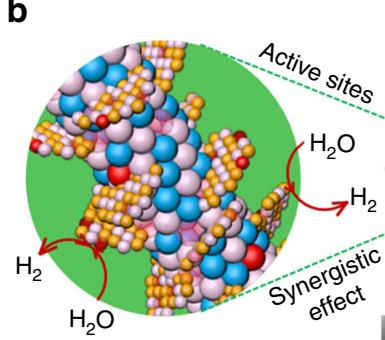

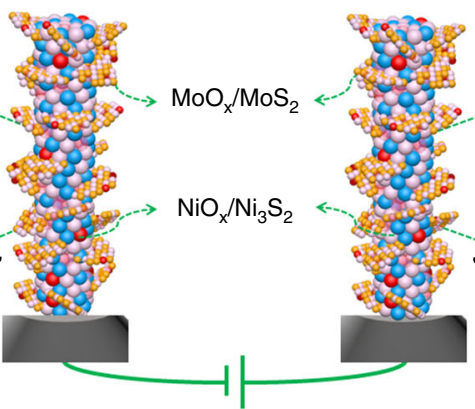

Hierarchical defective oxides/sulfides heterostructure array for overall water splitting

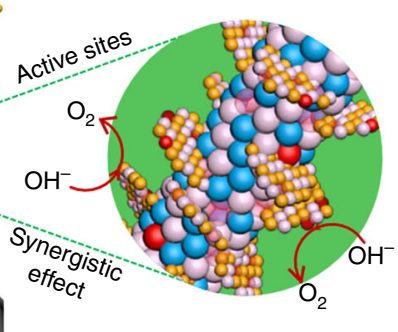

Oxygen evolution reaction

Fig. 1 Schematic representation of synthesis and overall water splitting. a Synthesis illustration of transition bimetal oxides/sulfides heterostructure array. b $\mathrm{NiMoO}_{x} / \mathrm{NiMoS}$ array as two-electrode-cell towards large-scale electrolysis. Colored balls represent various elements (blue: Mo, pink: S, red: O, yellow: $\mathrm{Ni}$ ).

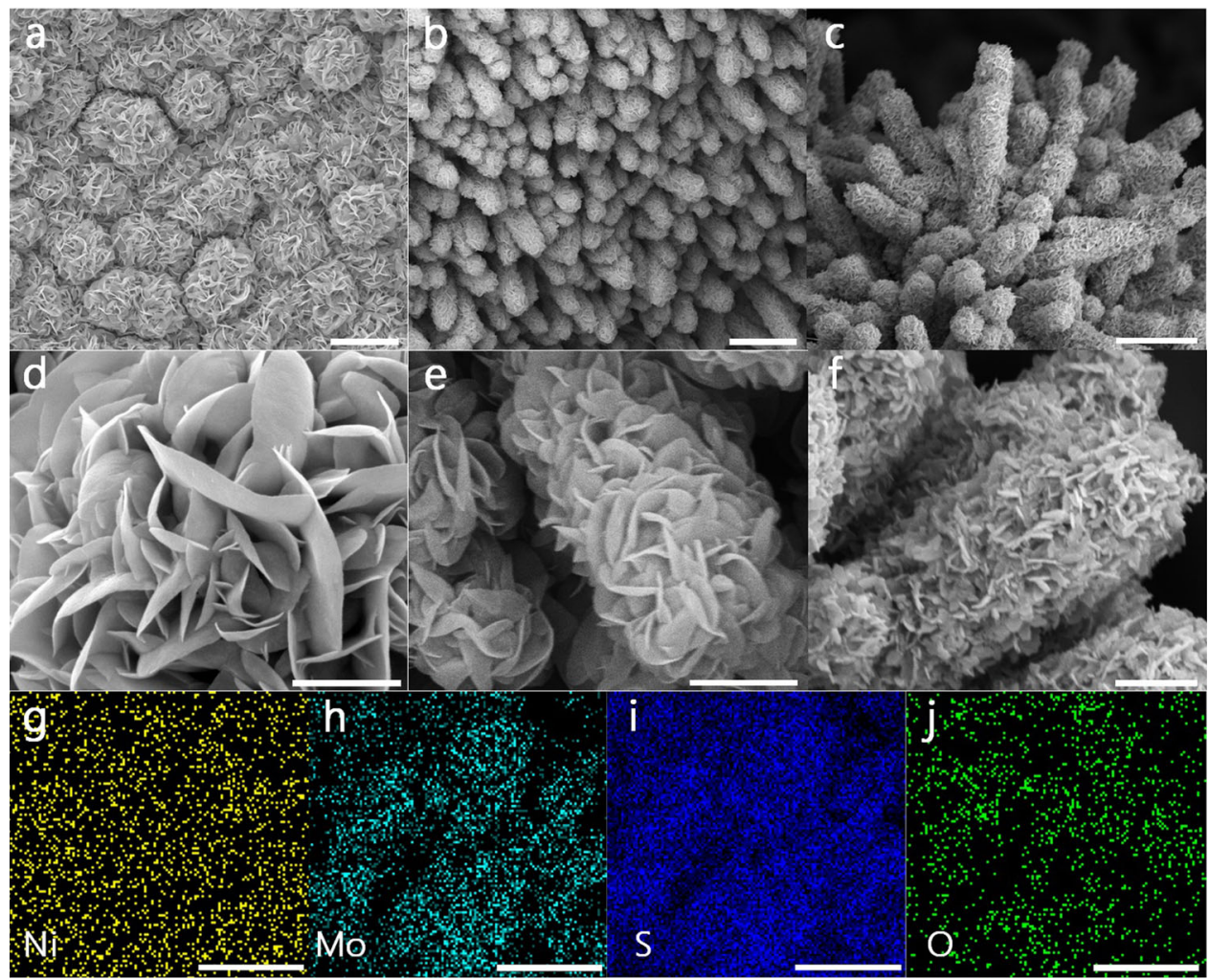

Fig. 2 Morphological and structural characterizations. SEM images of $\mathbf{a}, \mathbf{d} \mathrm{MoS}_{2}$, b, e NiMoS, c, $\mathbf{f} \mathrm{NiMoO}_{x} / \mathrm{NiMoS}$. g-j Elemental mapping images of $\mathrm{NiMoO}_{x} / \mathrm{NiMoS}$ Scale bar, a-c $5 \mu \mathrm{m}$; d-f $1 \mu \mathrm{m} ; \mathbf{g}-\mathbf{j} 10 \mu \mathrm{m}$. 


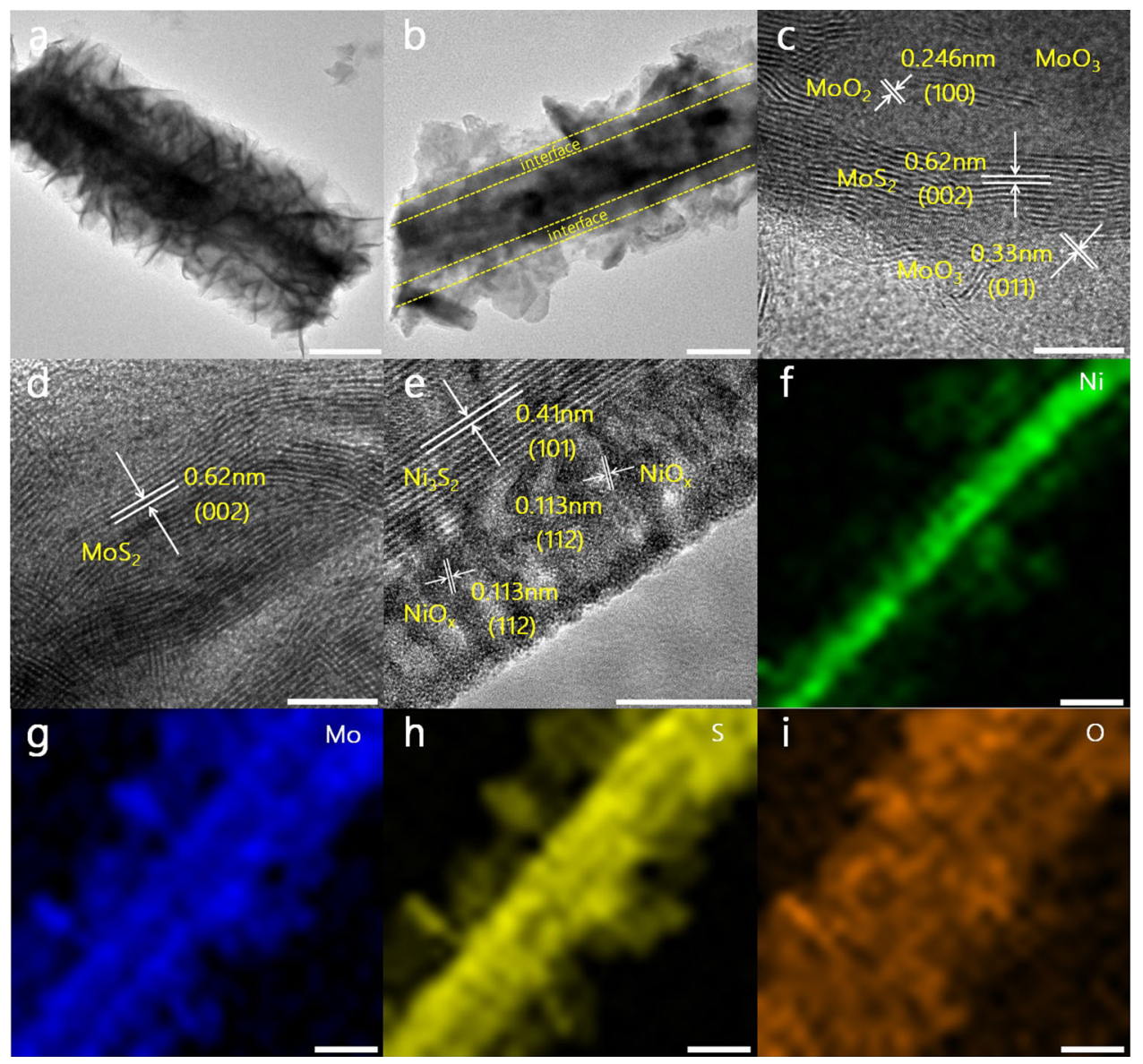

Fig. 3 Morphological and structural characterizations. TEM and HRTEM images of a, d NiMoS and $\mathbf{b}, \mathbf{c}, \mathbf{e}$ NiMoO $/ \mathrm{NiMoS}$. f-i Elemental distribution mapping of $\mathrm{Ni}, \mathrm{Mo}, \mathrm{S}$, and $\mathrm{O}$ in $\mathrm{NiMoO}_{x} / \mathrm{NiMoS}$. Scale bar, a, b $500 \mathrm{~nm}$; c-e $5 \mathrm{~nm}$; f-i $200 \mathrm{~nm}$.

elemental mapping (Fig. 2 and Supplementary Fig. 4) indicate the molar content of $\mathrm{MoO}_{x} / \mathrm{MoS}_{2}$ about $6.1 \%$ and the homogeneous element distribution in $\mathrm{NiMoO}_{x} / \mathrm{NiMoS}$ array. Thus, the abovementioned analysis indicates the formation of $\mathrm{NiMoO}_{x} / \mathrm{NiMoS}$ array as 3D integrated architectures.

To check the details of the morphology, transition electron microscope (TEM) and high-resolution TEM observations verify the architectures of $\mathrm{NiMoS}$ and $\mathrm{NiMoO}_{x} / \mathrm{NiMoS}$ heterostructure arrays, indicating that $\mathrm{MoS}_{2}$ and $\mathrm{MoO}_{x} / \mathrm{MoS}_{2}$ nanosheets are attached to $\mathrm{Ni}_{3} \mathrm{~S}_{2}$ and $\mathrm{NiO}_{x} / \mathrm{Ni}_{3} \mathrm{~S}_{2}$ nanorods arrays, respectively (Fig. 3). Compared to $\mathrm{MoS}_{2}$ and $\mathrm{Ni}_{3} \mathrm{~S}_{2}$ in NiMoS nanostructures, the characteristic lattice fringes of $0.62,0.33$, and $0.246 \mathrm{~nm}$ can be assigned to the (002) plane of $\mathrm{MoS}_{2}$, (011) plane of $\mathrm{MoO}_{3}$, and (100) plane of $\mathrm{MoO}_{2}$ and even more, the (101) plane of $\mathrm{Ni}_{3} \mathrm{~S}_{2}$ and the (112) plane of $\mathrm{NiO}_{x}$ can be proven by the lattice fringes of 0.41 and $0.113 \mathrm{~nm}$ in $\mathrm{NiMoO}_{x} / \mathrm{NiMoS}$ heterostructures. Typically, the arrangements of $\mathrm{MoO}_{\mathrm{x}}$ and $\mathrm{NiO}_{x}$ layers are observed on the surface of $\mathrm{MoS}_{2}$ and $\mathrm{Ni}_{3} \mathrm{~S}_{2}$, indicating the formation of $\mathrm{NiMoO}_{x} / \mathrm{NiMoS}$ heterostructure array. Moreover, the elemental mappings by high-angle annular dark-field scanning transmission electron microscopy (HAADF-STEM) confirm the uniform distribution of $\mathrm{Ni}, \mathrm{Mo}, \mathrm{S}$, and $\mathrm{O}$ (Fig. 3 and Supplementary Fig. 5). Therefore, the whole results of SEM and TEM analysis confirm the formation of $3 \mathrm{D} \mathrm{NiMoO}_{\mathrm{x}} / \mathrm{NiMoS}$ heterostructure array as the integrated architectures.

To conduct the chemical valences of the heterostructures, $\mathrm{X}$ ray photoelectron spectroscopy (XPS) spectrum has been tested in Fig. 4. With regard to Mo $3 d$ regions, the main peak could be split into two distinct peaks of Mo $3 d_{5 / 2}(229.1 \mathrm{eV})$ and Mo $3 d_{3 / 2}$ $(232.4 \mathrm{eV})$, indicating the dominance of $\mathrm{Mo}^{4+}$ in NiMoS

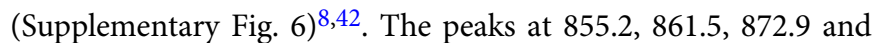
$879.5 \mathrm{eV}$ can be indexed to $\mathrm{Ni} 2 p_{3 / 2}$ and $\mathrm{Ni} 2 p_{1 / 2}$ orbitals as well as two satellites in NiMoS (Supplementary Fig. 6) ${ }^{25}$. However, the signals at $229.3,232.4$, and $235.5 \mathrm{eV}$ can be indexed to $\mathrm{Mo}^{4+} 3 d_{5 /}$ 2, $\mathrm{Mo}^{4+/ 6+} 3 d_{3 / 2}$, and $\mathrm{Mo}^{6+} 3 d_{3 / 2}$ orbitals, confirming the existence of $\mathrm{Mo}^{4+}$ and $\mathrm{Mo}^{6+}$ in $\mathrm{NiMoO}_{x} / \mathrm{NiMoS}$ owe to the formation of $\mathrm{MoO}_{\mathrm{x}}{ }^{26}$. For Ni 2p orbitals, there is a shift upon the peak positions and the two new peaks at 854.6 and $852.6 \mathrm{eV}$, demonstrating the existence of $\mathrm{Ni}-\mathrm{O}$ bonds and metallic $\mathrm{Ni}^{0}$ and the formation of $\mathrm{NiO}_{x}$ species in $\mathrm{NiMoO}_{x} / \mathrm{NiMoS}^{8,25}$. Typically, the signals at 529.5 and $531.5 \mathrm{eV}$ for $\mathrm{O} 1 \mathrm{~s}$ belong to typical metaloxygen bonds and oxygen vacancies in $\mathrm{NiMoO}_{x} / \mathrm{NiMoS}$ heterostructure $^{8}$. With regard to $S 2 p$ peaks, the negative shift is observed in $\mathrm{NiMoO}_{\mathrm{x}} / \mathrm{NiMoS}$ with the increasing temperature of thermal treatment, demonstrating the loss of $S$ and the formation of $\mathrm{S}$ vacancies ${ }^{43}$. The similar phenomenon of $\mathrm{O} 1 s$ and $\mathrm{S} 2 p$ is observed in $\mathrm{MoO}_{x} / \mathrm{MoS}_{2}$ and $\mathrm{NiO}_{x} / \mathrm{Ni}_{3} \mathrm{~S}_{2}$ heterostructures (Supplementary Fig. 7-8). Thus, the combined analysis demonstrates the successful synthesis of hierarchical transition bimetal oxides/sulfides heterostructure array.

Electrocatalytic HER performance. The electrocatalytic performance of various arrays in the three-electrode system was conducted through a linear scan voltammogram (LSV) in $1 \mathrm{M} \mathrm{KOH}$ solution at $25^{\circ} \mathrm{C}$. The polarization curves of $\mathrm{NiMoO}_{x} / \mathrm{NiMoS}$, $\mathrm{MoO}_{x} / \mathrm{MoS}_{2}, \mathrm{NiO}_{x} / \mathrm{Ni}_{3} \mathrm{~S}_{2}$, and $\mathrm{NiMoS}$ heterostructure arrays are presented in Fig. 5a, together with commercial Pt/C and Ni foam (Supplementary Fig. 9). In comparison of $\operatorname{NiMoS}(219,392$, and $611 \mathrm{mV}), \mathrm{MoO}_{x} / \mathrm{MoS}_{2}(163,282$, and $430 \mathrm{mV}), \mathrm{NiO}_{x} / \mathrm{Ni}_{3} \mathrm{~S}_{2}(67$, 

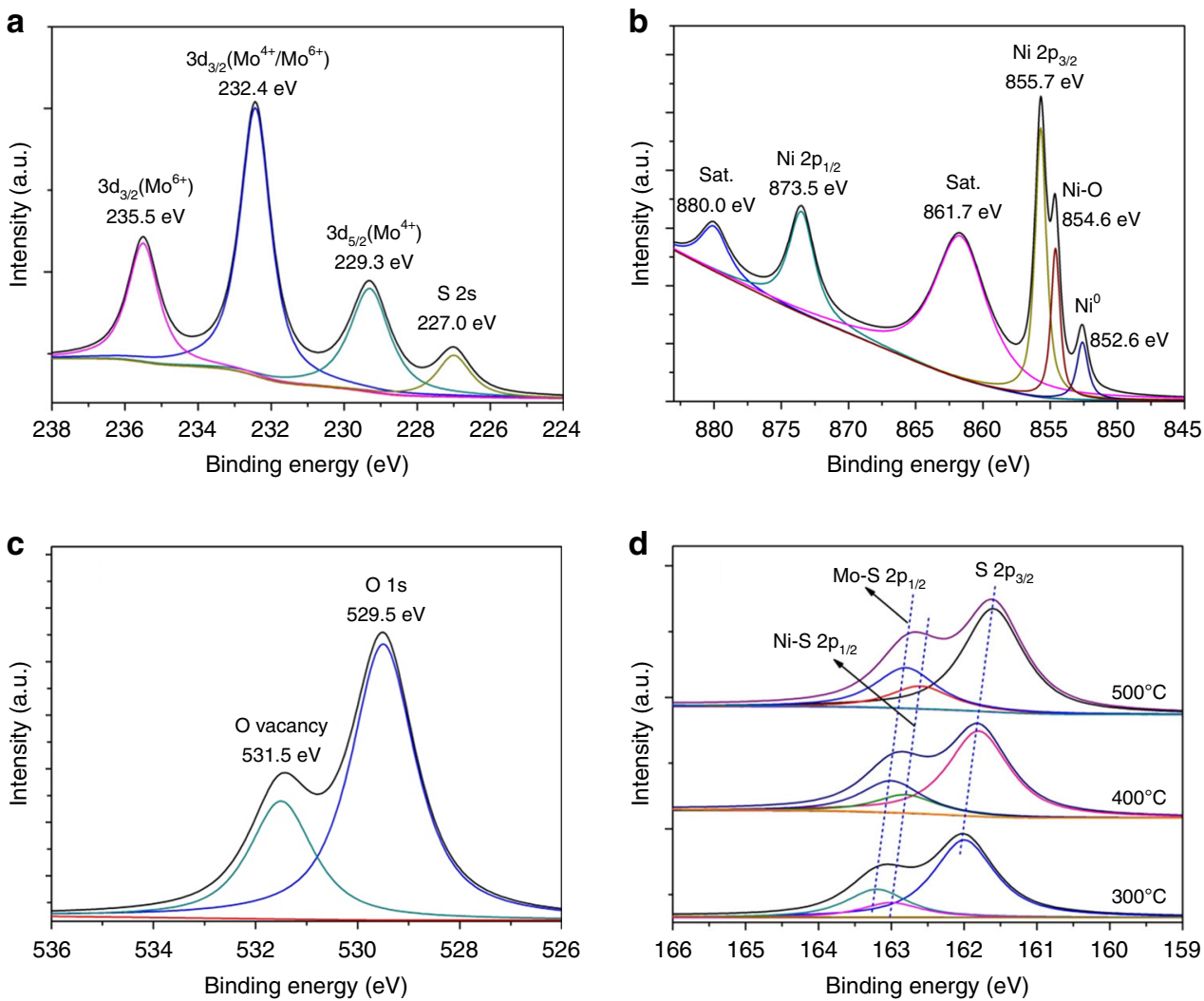

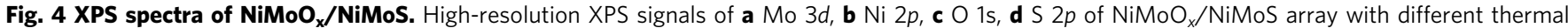
treatment temperatures.
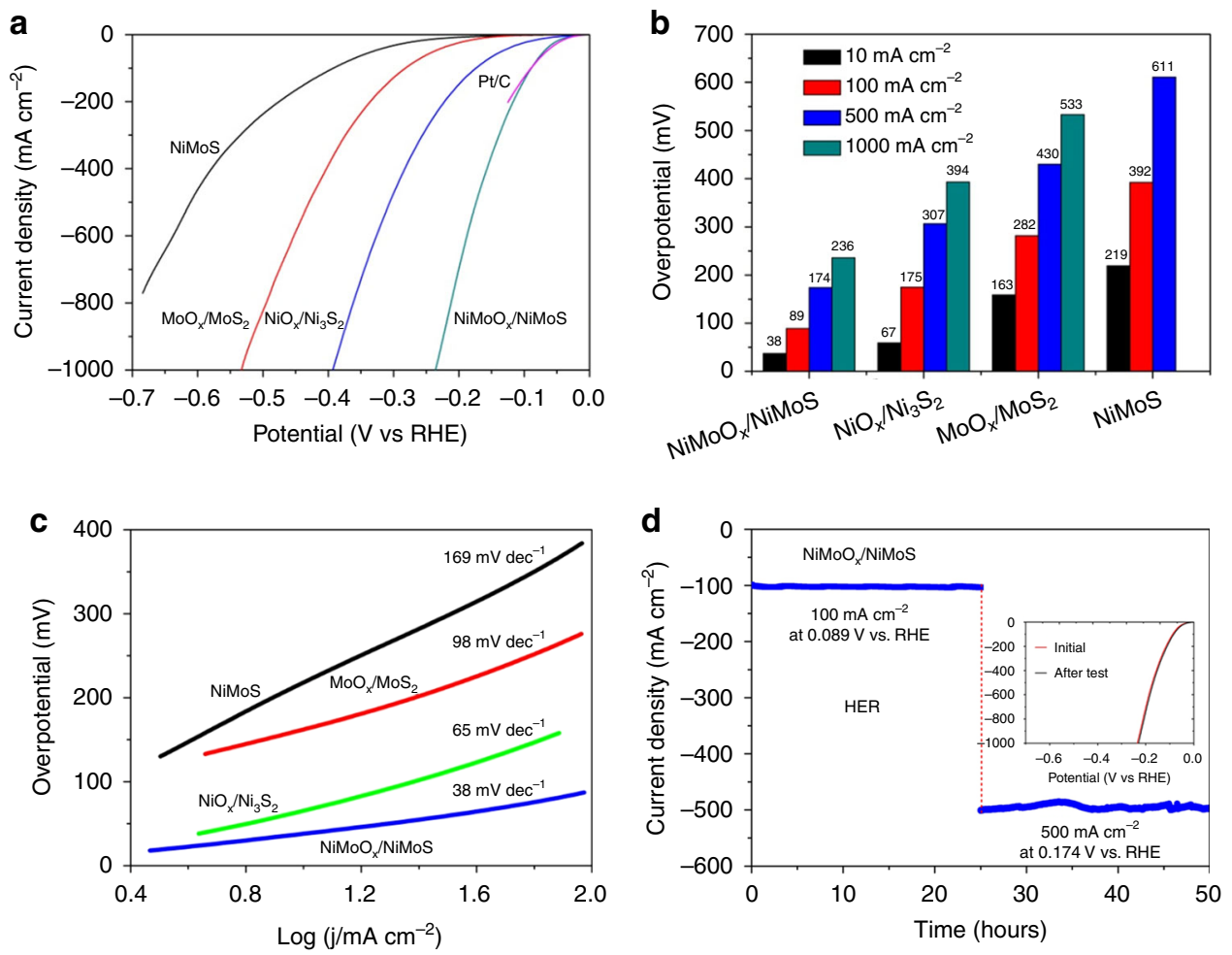

Fig. 5 HER catalytic performance. a HER polarization curves, b overpotentials at typical current densities, c Tafel slopes of NiMoS, MoO ${ }_{x} / \mathrm{MoS}_{2}, \mathrm{NiO}_{x} /$ $\mathrm{Ni}_{3} \mathrm{~S}_{2}$, and $\mathrm{NiMoO}_{x} / \mathrm{NiMoS}$. d Time-dependent current density curves of $\mathrm{NiMoO}_{x} / \mathrm{NiMoS}$ at typical potentials. Inset: polarization curves of $\mathrm{NiMoO} \times \mathrm{NiMoS}$ for the stability test. 
175, and $307 \mathrm{mV}$ ), $\mathrm{NiMoO}_{x} / \mathrm{NiMoS}$ array delivers the current densities of 10,100 , and $500 \mathrm{~mA} \mathrm{~cm}^{-2}$ at the low overpotentials of 38,89 and $174 \mathrm{mV}$, respectively, even requiring a low overpotential of $236 \mathrm{mV}$ at a large current density of $1000 \mathrm{~mA} \mathrm{~cm}^{-2}$ towards HER (Fig. 5b). It is worth mentioning that $\mathrm{NiMoO}_{x} /$ NiMoS array could surpass commercial $\mathrm{Pt} / \mathrm{C}$ catalyst at the high overpotentials while comparable HER activity at the low potentials. Compared to most reported HER catalysts (Supplementary Table 1), the overpotential of $\mathrm{NiMoO}_{x} / \mathrm{NiMoS}$ array at a current density of $10 \mathrm{~mA} \mathrm{~cm}^{-2}$ is smaller than those of $\mathrm{MoS}_{2}(170 \mathrm{mV})^{44}$, CoFeZr oxides $(104 \mathrm{mV})^{6}, \mathrm{CoS}-\mathrm{Co}(\mathrm{OH})_{2} @ \mathrm{MoS}_{2+x}(140 \mathrm{mV})^{26}$, $\mathrm{MoS}_{2} / \mathrm{Fe}_{5} \mathrm{Ni}_{4} \mathrm{~S}_{8}(120 \mathrm{mV})^{27}, \mathrm{MoS}_{2} / \mathrm{Ni}_{3} \mathrm{~S}_{2}(110 \mathrm{mV})^{28}, \mathrm{MoS}_{2} /$ $\mathrm{Co}_{9} \mathrm{~S}_{8} / \mathrm{Ni}_{3} \mathrm{~S}_{2}(113 \mathrm{mV})^{30}$, and O-CoMoS $(97 \mathrm{mV})^{42}$, etc. To regulate the capacities of charge transfer and active sites of NiMoS, it is interesting to determine the precise condition of plasma oxidation and hydrogenation treatment (Supplementary Fig. 10), indicating the best oxygen plasma power of $100 \mathrm{~W}$ and appropriate hydrogenation temperature of $400{ }^{\circ} \mathrm{C}$ of $\mathrm{NiMoO}_{x} / \mathrm{NiMoS}$ array. To conduct HER kinetic mechanism, the lowest Tafel slope (Fig. $5 \mathrm{c}$ ), $38 \mathrm{mV}$ per decade of $\mathrm{NiMoO}_{x} / \mathrm{NiMoS}$ array is obtained in comparison of $\mathrm{NiO}_{x} / \mathrm{Ni}_{3} \mathrm{~S}_{2}\left(65 \mathrm{mV} \mathrm{dec}{ }^{-1}\right), \mathrm{MoO}_{x} / \mathrm{MoS}_{2}$ (98 $\left.\mathrm{mV} \operatorname{dec}^{-1}\right)$, NiMoS $\left(169 \mathrm{mV} \mathrm{dec}^{-1}\right)$, indicating the rapid HER kinetics of $\mathrm{NiMoO}_{\mathrm{x}} / \mathrm{NiMoS}$ array owe to the advantages of the construction of $3 \mathrm{D}$ heterostructured architectures and the introduction of the defects. After the analysis of electrochemical impedance spectroscopy (EIS), the lowest charge transfer resistance of $\mathrm{NiMoO}_{x} / \mathrm{NiMoS}$ array due to the generation of defective species and metallic $\mathrm{Ni}$ is obtained in comparison of $\mathrm{NiO}_{x} / \mathrm{Ni}_{3} \mathrm{~S}_{2}$, $\mathrm{MoO}_{\mathrm{x}} / \mathrm{MoS}_{2}$, and NiMoS (Supplementary Fig. 10). To explore the intrinsic electrocatalytic performance of each active sites, the turnover frequency (TOF) is calculated (Supplementary Table 2-3). The TOF value of $\mathrm{NiMoO}_{x} / \mathrm{NiMoS}$ array $\left(1.97 \mathrm{~s}^{-1}\right)$ at the overpotential of $100 \mathrm{mV}$ is $\sim 45$ times higher than that of NiMoS array $\left(0.0435 \mathrm{~s}^{-1}\right)$. Moreover, mass activity, $436 \mathrm{~A} \mathrm{~g}^{-1}$ of $\mathrm{NiMoO}_{x} / \mathrm{NiMoS}$ array is calculated at the overpotential of $200 \mathrm{mV}$ (Supplementary Fig. 11), which is better than other nonnobel metal electrocatalysts (Supplementary Table 4). Generally, the electrochemically active surface area (ECSA) is regarded as an estimation of active sites and is proportional to the double-layer capacitance $\left(C_{\mathrm{dl}}\right)^{45-47}$. The highest $C_{\mathrm{dl}}$ values of $\mathrm{NiMoO}_{x} / \mathrm{NiMoS}$ array among all catalysts implies the maximum electroactive area (Supplementary Fig. 12). Moreover, the current of $\mathrm{NiMoO}_{x}$ l $\mathrm{NiMoS}$ and commercial Pt/C supported on Ni plate was normalized to ECSA (Supplementary Figs. 13-16), demonstrating a higher instrinsic activity of $\mathrm{NiMoO}_{\mathrm{x}} / \mathrm{NiMoS}$ catalyst in comparison of commercial $\mathrm{Pt} / \mathrm{C}$. Owe to the stability as pivot criterion for practical application, the time-dependent current density curves confirm that there is no obvious change upon the current densities of 100 and $500 \mathrm{~mA} \mathrm{~cm}^{-2}$ at 0.089 and $0.174 \mathrm{~V}$ vs. RHE over $50 \mathrm{~h}$ (Fig. 5d). Afterwards, the amount of hydrogen evolution of $\mathrm{NiMoO}_{\mathrm{x}} / \mathrm{NiMoS}$ array is measured in comparison of theoretical quantity (Supplementary Fig. 17), presenting a promising Faradaic efficiency of $99.6 \pm 0.3 \%$ towards real water splitting into hydrogen. Based on the above-mentioned analysis, the synergistic action of morphology and heterostructure engineering upon $\mathrm{NiMoO}_{\mathrm{x}} / \mathrm{NiMoS}$ array can modulate the unique architectures, optimize the charge transfer and catalytic active sites, and thus improve HER performance.

Electrocatalytic OER performance. In general, the efficiency is always limited by OER as major barrier for overall water splitting. In our system, $\mathrm{NiMoO}_{x} / \mathrm{NiMoS}$ array exhibits the best OER performance among all arrays, together with commercial $\mathrm{IrO}_{2}$ catalyst and $\mathrm{Ni}$ foam (Fig. 6a and Supplementary Fig. 18). In comparison of $\mathrm{NiMoS}(370,437$, and $526 \mathrm{mV}), \mathrm{MoO}_{x} / \mathrm{MoS}_{2}(266,332$, and
$438 \mathrm{mV}), \mathrm{NiO}_{x} / \mathrm{Ni}_{3} \mathrm{~S}_{2}(214,267$, and $366 \mathrm{mV})$, as-synthesized $\mathrm{NiMoO}_{\mathrm{x}} / \mathrm{NiMoS}$ array presents the low overpotentials of 186, 225, and $278 \mathrm{mV}$ at current densities of 10,100 , and $500 \mathrm{~mA} \mathrm{~cm}^{-2}$, and delivers a large current density of $1000 \mathrm{~mA} \mathrm{~cm}^{-2}$ at $334 \mathrm{mV}$ towards OER (Fig. 6b), satisfying the requirements for commercial electrocatalytic application (for example, $j \geq 500 \mathrm{~mA} \mathrm{~cm}^{-2}$ at $\eta \leq$ $300 \mathrm{mV})^{48-51}$. Compared to most reported OER catalysts (Supplementary Table 5), the overpotential of $\mathrm{NiMoO}_{x} / \mathrm{NiMoS}$ array at $10 \mathrm{~mA} \mathrm{~cm}^{-2}$ is still lower than those of O-CoMoS $(272 \mathrm{mV})^{42}$, $\mathrm{CoS}-\mathrm{Co}(\mathrm{OH})_{2} @ \mathrm{MoS}_{2+x}(380 \mathrm{mV})^{26}, \mathrm{MoS}_{2} / \mathrm{Fe}_{5} \mathrm{Ni}_{4} \mathrm{~S}_{8}(204 \mathrm{mV})^{27}$, $\mathrm{MoS}_{2} / \mathrm{Ni}_{3} \mathrm{~S}_{2}(218 \mathrm{mV})^{28}$, and iron-substrate-derived electrocatalyst $(269 \mathrm{mV})^{48}$, etc. Especially, the influence of oxygen plasma power and hydrogenation temperature upon the OER performance of $\mathrm{NiMoO}_{x} / \mathrm{NiMoS}$ array is determined (Supplementary Fig. 19), confirming the best plasma power of $100 \mathrm{~W}$ and thermal treatment temperature at $400{ }^{\circ} \mathrm{C}$ of $\mathrm{NiMoO}_{x} / \mathrm{NiMoS}$ array. To in-depth understand the OER kinetic mechanism, the lowest Tafel slope, $34 \mathrm{mV}$ per decade of $\mathrm{NiMoO}_{x} / \mathrm{NiMoS}$ is achieved in comparison of $\mathrm{NiO}_{x} / \mathrm{Ni}_{3} \mathrm{~S}_{2}\left(56 \mathrm{mV} \mathrm{dec}^{-1}\right), \mathrm{MoO}_{x}$ l $\mathrm{MoS}_{2}\left(62 \mathrm{mV} \mathrm{dec}^{-1}\right)$, NiMoS $\left(74 \mathrm{mV} \mathrm{dec}^{-1}\right)$, demonstrating the fast OER kinetics of $\mathrm{NiMoO}_{\mathrm{x}} / \mathrm{NiMoS}$ (Fig. 6c). Remarkably, the largest $C_{\mathrm{dl}}$ value of $21.5 \mathrm{mF} \mathrm{cm}{ }^{-2}$ of $\mathrm{NiMoO}_{\mathrm{x}} / \mathrm{NiMoS}$ is obtained by the evaluation of ECSA among all arrays (Supplementary Fig. 20), indicating the production of abundant active sites in $\mathrm{NiMoO}_{x} / \mathrm{NiMoS}$ array. Especially, the high ECSA of $\mathrm{NiMoO}_{x} /$ NiMoS array confirms the advantages of the exposured component and geometric structures of sufficient electrocatalytic active sites. Interestingly, the high-valence $\mathrm{Mo}$ and $\mathrm{Ni}$ species are obtained in $\mathrm{NiMoO}_{x} / \mathrm{NiMoS}$ array during the OER process (Supplementary Fig. 24), indicating the possible generation of hydroxyl oxides as the actual surface active sites and thus enhancing the OER activities owe to the synergistic action of $3 \mathrm{D}$ architectures and the heterostructures. In particular, $\mathrm{NiMoO}_{x} /$ NiMoS array can preserve OER activities at 100 and $500 \mathrm{~mA} \mathrm{~cm}^{-2}$ with the potentials of 1.455 and $1.508 \mathrm{~V}$ vs. RHE over $50 \mathrm{~h}$ (Fig. 6d), indicating the fascinating OER stability. Typically, the amount of oxygen evolution of $\mathrm{NiMoO}_{\mathrm{x}} / \mathrm{NiMoS}$ array is measured in comparison of theoretical quantity (Supplementary Fig. 21), presenting OER Faradaic efficiency of $97.5 \pm 0.4 \%$ owe to the synergistic effect of the morphology and heterostructure engineering.

Electrocatalytic performance for overall water splitting. Inspired by excellent HER and OER performance, $\mathrm{NiMoO}_{x} /$ NiMoS array was assembled as cathode and anode in the twoelectrode system. Impressively, the robust catalytic performance is achieved by as-synthesized $\mathrm{NiMoO}_{x} / \mathrm{NiMoS} \mid \mathrm{NiMoO}_{x} / \mathrm{NiMoS}$ electrode (Fig. 7a), requiring the low cell voltages of $1.46,1.62$, 1.75 , and $1.82 \mathrm{~V}$ at $10,100,500$, and $1000 \mathrm{~mA} \mathrm{~cm}^{-2}$ in $1 \mathrm{M} \mathrm{KOH}$ at $25^{\circ} \mathrm{C}$. In comparison of $\mathrm{Ni}-\mathrm{Fe}-\mathrm{MoN}^{52}, \mathrm{Fe}_{0.09} \mathrm{Co}_{0.13}-\mathrm{NiSe}_{2}{ }^{53}$, $\mathrm{NC} / \mathrm{CoCu} / \mathrm{CoCuO}{ }_{\mathrm{x}}{ }^{20}, \quad \mathrm{MoS}_{2} / \mathrm{Co}_{9} \mathrm{~S}_{8} / \mathrm{Ni}_{3} \mathrm{~S}_{2}{ }^{30}, \quad \mathrm{Pt}-\mathrm{CoS}_{2}{ }^{47}, \quad \mathrm{NC} /$ $\mathrm{NiCu} / \mathrm{NiCuN}{ }^{25}, \mathrm{NC} / \mathrm{NiMo} / \mathrm{NiMoO}_{x}{ }^{8}, \mathrm{MoS}_{2} / \mathrm{NiS}_{2}{ }^{54}, \mathrm{O}-\mathrm{CoMoS}^{42}$, $\mathrm{N}-\mathrm{NiMoO}_{4} / \mathrm{NiS}_{2}{ }^{15}, \mathrm{MoS}_{2} / \mathrm{NiS}^{55}, \mathrm{P}-\mathrm{Co}_{3} \mathrm{O}_{4}{ }^{56}, \mathrm{Ni} / \mathrm{Mo}_{2} \mathrm{C}^{57}, \mathrm{CoNi}$ $(\mathrm{OH})_{\mathrm{x}} \mid \mathrm{NiN}_{x}{ }^{58}, \mathrm{NiCo}_{2} \mathrm{~S}_{4}{ }^{59}, \mathrm{FeOOH}^{60}, \mathrm{Ni}_{5} \mathrm{P}_{4}{ }^{61}, \mathrm{NiCo} / \mathrm{NiCoO}_{x}{ }^{62}$, $\mathrm{Fe}-\mathrm{Ni} @ \mathrm{NC}-\mathrm{CNT}^{63}, \mathrm{Co}_{x} \mathrm{PO}_{4} / \mathrm{CoP}^{64}$, and commercial $\mathrm{Pt} / \mathrm{C} \| \mathrm{IrO}_{2}$ electrodes (Fig. 7c and Supplementary Table 6), the lower voltage at $10 \mathrm{~mA} \mathrm{~cm}^{-2}$ is obtained for $\mathrm{NiMoO}_{x} / \mathrm{NiMoS}$ array. Owe to excellent electrocatalytic performance, the two-electrode cell can also be evaluated by a $1.5 \mathrm{~V}$ AAA battery (Supplementary Fig. 22). Based on the analysis of the superaerophobicity by bubble contact tests (Supplementary Fig. 23), the superior bubble contact angle, $151.2^{\circ}$ of $\mathrm{NiMoO}_{x} / \mathrm{NiMoS}$ is obtained, demonstrating that this typical architecture could facilitate the release of the evolved gas bubbles and thus avoid the block of the catalyst active site. To be interesting, the hydrogen and oxygen bubbles 

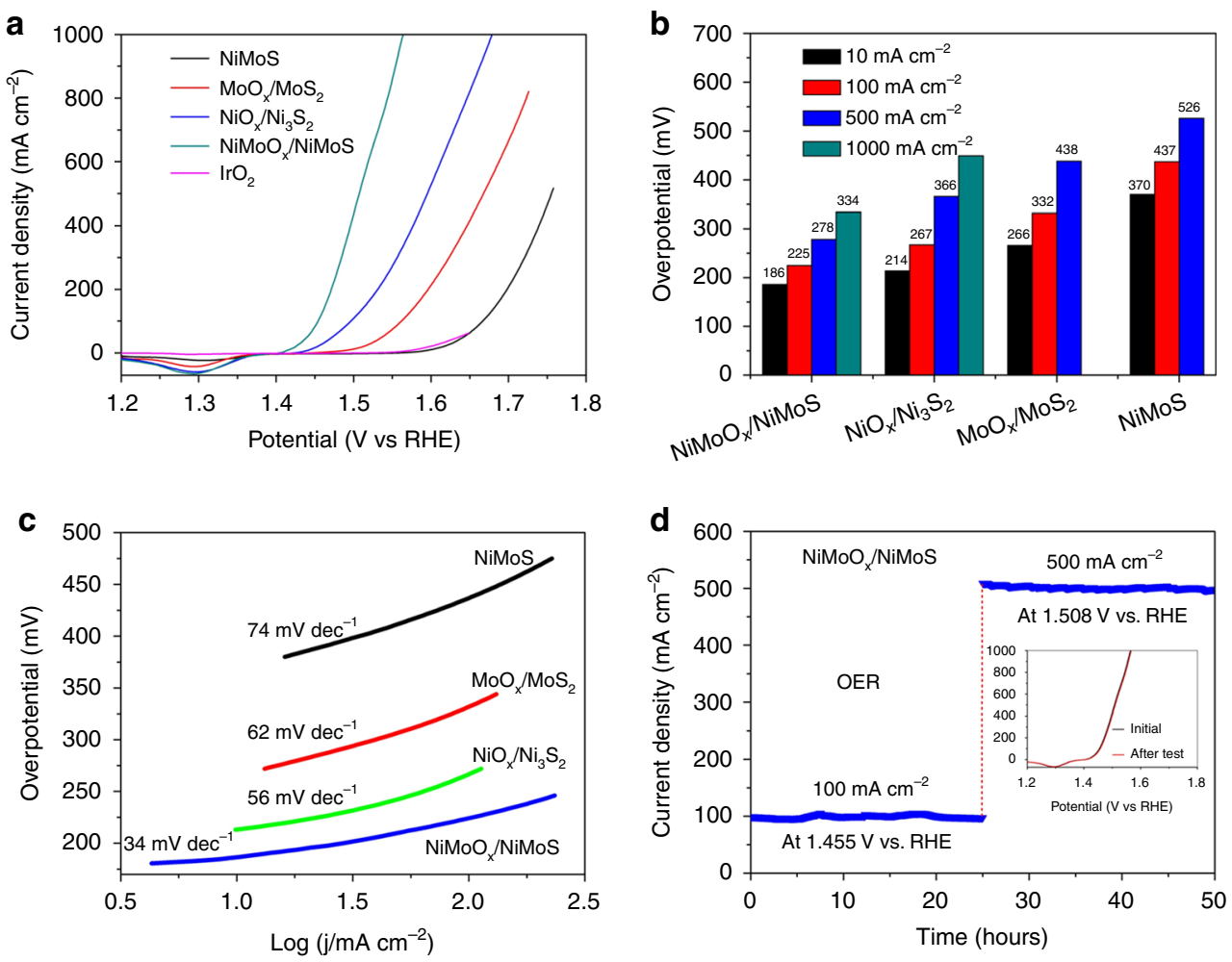

Fig. 6 OER catalytic performance. a OER polarization curves, b overpotentials at typical current densities, c Tafel slopes of $\mathrm{NiMoS}_{1} \mathrm{MoO}_{x} / \mathrm{MoS}_{2}, \mathrm{NiO}_{x} /$ $\mathrm{Ni}_{3} \mathrm{~S}_{2}$, and $\mathrm{NiMoO}_{x} / \mathrm{NiMoS}$. d Time-dependent current density curves of $\mathrm{NiMoO}_{x} / \mathrm{NiMoS}$ at typical potentials. Inset: polarization curves of $\mathrm{NiMoO} \times / \mathrm{NiMoS}$ for the durability test.

escape effectively from the surface of $\mathrm{NiMoO}_{x} / \mathrm{NiMoS}$ array (Supplementary Movie). Moreover, the industrial environment is employed to explore the potential for industrialization applications. Typically, the record low voltages of 1.60 and $1.66 \mathrm{~V}$ of the two-electrode system in $6 \mathrm{M} \mathrm{KOH}$ solution at $60^{\circ} \mathrm{C}$ are achieved for the industrial current densities of 500 and $1000 \mathrm{~mA} \mathrm{~cm}^{-2}$, respectively, and it is still better than that of $\mathrm{Pt} / \mathrm{C} \| \mathrm{IrO}_{2}$ couple (Fig. 7b and Supplementary Tabel 7). Compared to the reported electrocatalysts with the large current densities (e.g., 500 and $1000 \mathrm{~mA} \mathrm{~cm}^{-2}$ ), such as NiMoN@NiFeN ${ }^{65}$, nickel-cobalt complexes hybridized $\mathrm{MoS}_{2}{ }^{66}$, Ni-P-B/paper ${ }^{49}$, NiVIr-LDH $\| \mathrm{NiVRu}$ $\mathrm{LDH}^{50}$, phosphorus-doped $\mathrm{Fe}_{3} \mathrm{O}_{4}{ }^{51}$, graphdiyne-sandwiched layered double-hydroxide nanosheets ${ }^{67}, \mathrm{~N}, \mathrm{~S}$-coordinated Ir nanoclusters embedded on N,S-doped graphene ${ }^{68}, \mathrm{Co}_{3} \mathrm{Mo} / \mathrm{Cu}^{69}$, and $\mathrm{FeP} / \mathrm{Ni}_{2} \mathrm{P}$ hybrid ${ }^{70}$, all aforementioned analysis confirm that as-prepared $\mathrm{NiMoO}_{x} / \mathrm{NiMoS}$ array could be served as promising industrial candidate for overall water splitting. With regard to the operating stability as important metric, this typical two-electrode cell can maintain the excellent electrocatalytic activity at a large current density of $500 \mathrm{~mA} \mathrm{~cm}^{-2}$ at the voltage of $1.75 \mathrm{~V}$ over 500 $\mathrm{h}$ without obvious degradation in $1 \mathrm{M} \mathrm{KOH}$ solution at $25^{\circ} \mathrm{C}$ (Fig. 7d). After HER, there is no obvious change upon the binding energies of various metal ions (Supplementary Fig. 24). However, the positive shift of two peaks located at 856.3 and $874.1 \mathrm{eV}$ is observed in the XPS of Ni 2p, demonstrating that the oxidation of $\mathrm{Ni}^{2+}$ to high valence state of $\mathrm{Ni}^{3+}$, alone with the existence of new peak at $869.05 \mathrm{eV}$ (Supplementary Fig. 24), thus indicating the formation of hydroxides and oxyhydroxides as the real active sites during OER process ${ }^{30-34}$. Although the hydroxides and oxyhydroxides are formed on the surface of $\mathrm{NiMoO}_{\mathrm{x}} / \mathrm{NiMoS}$ array, there is no apparent change upon the morphology of the heterostructures (Supplementary Fig. 25), indicating the superior stability. Based on the above analysis, it is proven that $\mathrm{NiMoO}_{x} /$
NiMoS array is excellent and stable system for overall water splitting, presenting the industrial hope.

First-principles calculations. To explore the original relationship between the intrinsically catalytic activity and the electronic and atomic structures of the interface of $\mathrm{NiMoO}_{x} / \mathrm{NiMoS}$, density functional theory calculations were performed to conduct the Gibbs free energies of every step in HER and OER (Supplementary Fig. 26-33). The hydrogen absorption energy $\left(\Delta G_{\mathrm{H}^{*}}\right)$ is generally considered as the key descriptor for evaluating the performance of $\mathrm{HER}^{71}$. The sulfur sites of $\mathrm{NiO}_{x} / \mathrm{Ni}_{3} \mathrm{~S}_{2}$ and $\mathrm{MoO}_{x} /$ $\mathrm{MoS}_{2}$ exhibit much lower $\Delta G_{\mathrm{H}^{*}}$ relative to that of $\mathrm{Ni}_{3} \mathrm{~S}_{2}$ and $\mathrm{MoS}_{2}$ (Fig. 8a and Supplementary Fig. 29-32), indicating that the integration of the oxides and sulfides enables the favorable $\mathrm{H}^{*}$ adsorption and the tremendous decrement of thermodynamic barriers for hydrogen production. Especially, the oxidation/ hydrogenation-induced surface reconfiguration results into the fabrication of $\mathrm{NiMoO}_{x} / \mathrm{NiMoS}$ heterostructure. The sulfur species serve as the distinctive active sites for the optimized hydrogen adsorption with nearly zero $\Delta G_{\mathrm{H}^{*}}(0.003 \mathrm{eV})$, in comparison of $\mathrm{NiO}_{x} / \mathrm{Ni}_{3} \mathrm{~S}_{2}\left(\Delta G_{\mathrm{H}^{*}}=0.074 \mathrm{eV}\right)$ and $\mathrm{MoO}_{x} / \mathrm{MoS}_{2}\left(\Delta G_{\mathrm{H}^{*}}=0.422\right.$ $\mathrm{eV})$. Since oxygen-free NiMoS shows much more negative $\Delta G_{\mathrm{H}^{*}}$ $(-0.284 \mathrm{eV})$ comparing to $\mathrm{NiMoO}_{\mathrm{x}} / \mathrm{NiMoS}$, it is hypothesized that the oxide species of the unique multi-interfaces may avoid the excessively strong adsorption of $\mathrm{H}^{*}$ and bring about the facile intermediates desorption. Theoretically, water oxidation in alkaline medium involves four concerted proton-electron transfer steps $^{72}$. The absorption configurations and calculated free energy profiles of OER steps are presented (Figs. 8b-8d). Obviously, the potential rate-determining step (PDS) of NiMoS heterostructures is the third electrochemical step from ${ }^{*} \mathrm{O}$ to ${ }^{*} \mathrm{OOH}$ with an energy barrier of $1.80 \mathrm{eV}$. The ${ }^{*} \mathrm{OOH}$ species on $\mathrm{NiMoO}_{x} / \mathrm{NiMoS}$ 

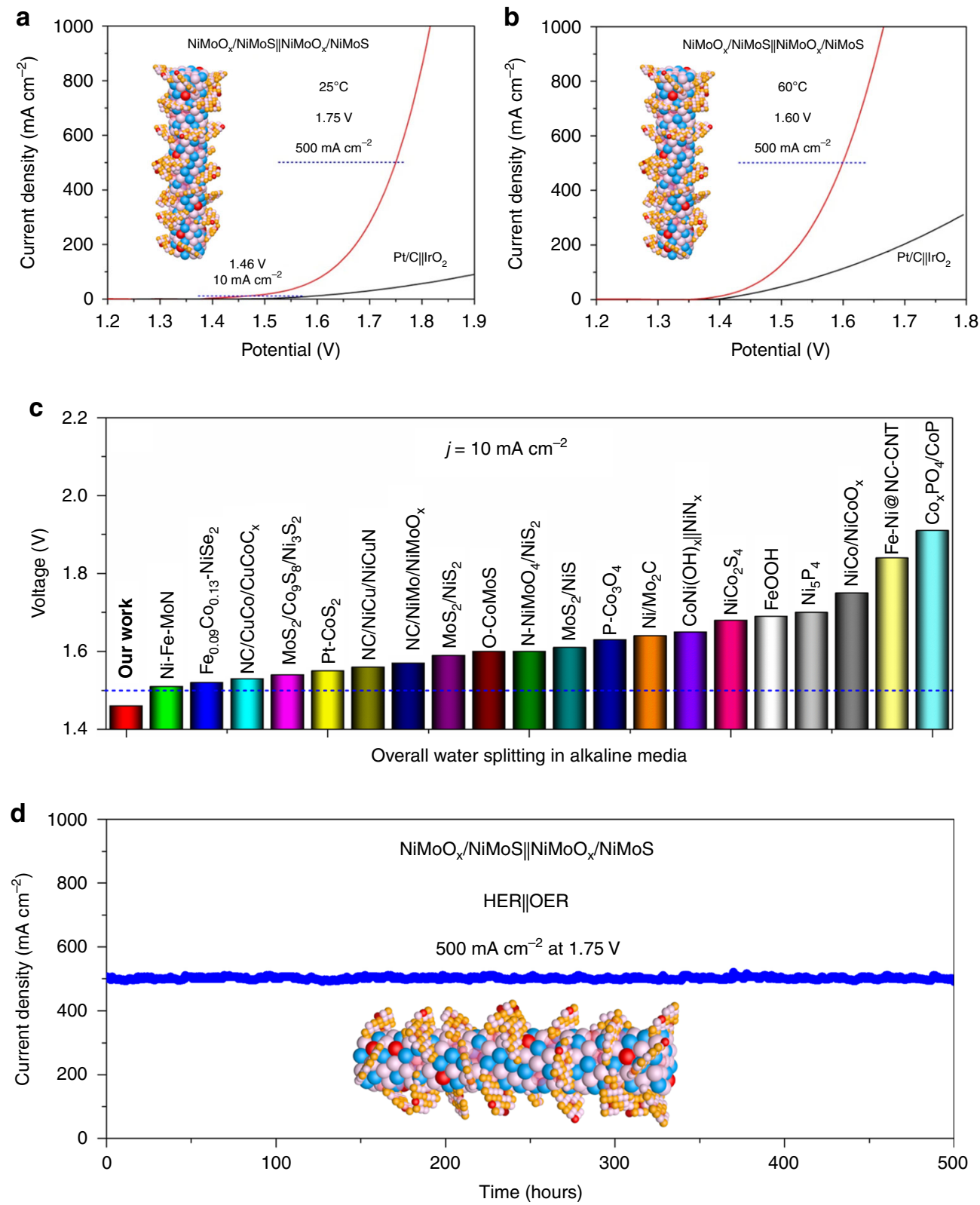

Fig. 7 Electrocatalytic performance for overall water splitting. a, b Polarization curves by two-electrode system in $\mathbf{a} 1 \mathrm{M} \mathrm{KOH}$ at $25^{\circ} \mathrm{C}$ and $\mathbf{b} 6 \mathrm{M} \mathrm{KOH}$ at $60^{\circ} \mathrm{C}$. c Comparison of the cell voltage at $10 \mathrm{~mA} \mathrm{~cm}^{-2}$ for $\mathrm{NiMoO}_{x} / \mathrm{NiMoS}^{\circ}$ with previously reported catalysts $8,15,20,25,30,42,47,52-64$. d Chronoamperometric test at $1.75 \mathrm{~V}$ in $1.0 \mathrm{M} \mathrm{KOH}$ at $25^{\circ} \mathrm{C}$.

heterostructures are greatly stabilized and overpotential is largely reduced to $0.85 \mathrm{~V}$ with the PDS of forming molecule $\mathrm{O}_{2}$. In comparison of $\mathrm{NiMoO}_{x} / \mathrm{NiMoS}$, it is of noted that the oxide species in $\mathrm{NiO}_{x} / \mathrm{Ni}_{3} \mathrm{~S}_{2}$ and $\mathrm{MoO}_{x} / \mathrm{MoS}_{2}$ heterointerfaces have small evident impact on the decrement of overpotential (Supplementary Fig. 29-32). Therefore, the multi-interfaces of bimetal oxides/sulfides heterostructures are indispensible for the favorable stabilization of intermediates and accelerated electrochemical kinetics. In order to undestand the charge transfer between the $\mathrm{NiMoO}_{x} / \mathrm{NiMoS}$ interface, charge density difference was performed (Supplementary Fig. 33). It is clear that a remarkable charge transfer across the interface, facilitates the fast electron transfer during the electrocatalytic process. Overall, the theory simulations and experiments demonstrate that the excellent OER and HER activities are facilitated by the synergetic effect of the oxidation/hydrogenation-induced surface reconfiguration.
In this case, the robust electrocatalytic activity is firstly ascribed to $3 \mathrm{D}$ hierarchical heterostructures of $\mathrm{NiMoO}_{\mathrm{x}} / \mathrm{NiMoS}$ array owe to the excellent mass transport and gas permeability. Secondly, the constructed interfaces among various heterostructures not only produce together the activities of different materials, but also facilitate the charge transfer and brings exceptionally synergistic effect of typical catalysts by oxidation/hydrogenation-induced surface reconfiguration strategy. Thirdly, the generation of defective species in hierarchical heterostructures could optimize electric conductivity and generate abundant active sites, confirming by low resistances and large ECSAs. Finally, the synergistic effect of the morphology and heterostructure engineering in $\mathrm{NiMoO}_{\mathrm{x}} / \mathrm{NiMoS}$ array promotes the generation of abundant active sites by engineering active sites, optimizing adsorption energies, and accelerating water splitting kinetics. All advantages promote the robust catalytic performance of $\mathrm{NiMoO}_{\mathrm{x}} / \mathrm{NiMoS}$ 
a

HER

$\mathrm{Ni}_{3} \mathrm{~S}_{2} / \mathrm{MoS}_{2}$

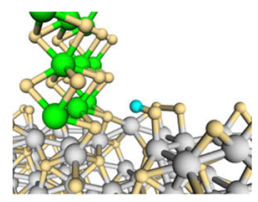

$\Delta G_{\mathrm{H}^{\star}}=-0.284 \mathrm{eV}$
$\mathrm{NiMoO}_{x} / \mathrm{NiMoS}$

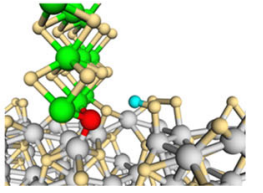

$\Delta G_{\mathrm{H}^{*}}=0.003 \mathrm{eV}$
$\mathrm{NiO}_{x} / \mathrm{Ni}_{3} \mathrm{~S}_{2}$

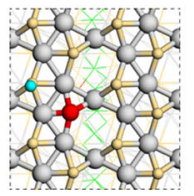

$\Delta G_{\mathrm{H}^{*}}=0.074 \mathrm{eV}$
$\mathrm{MoO}_{x} / \mathrm{MoS}_{2}$

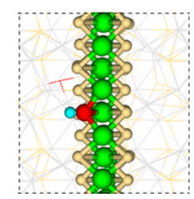

$\Delta G_{\mathrm{H}^{*}}=0.422 \mathrm{eV}$
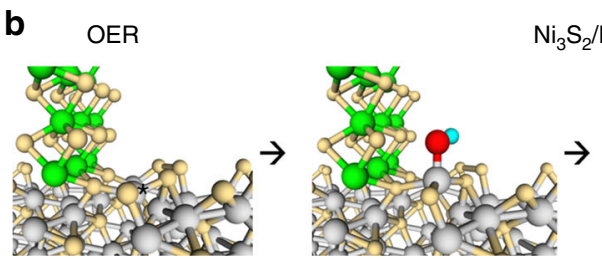

$\mathrm{Ni}_{3} \mathrm{~S}_{2} / \mathrm{MoS}_{2} \bigcirc \mathrm{H} \bigcirc \mathrm{S}$

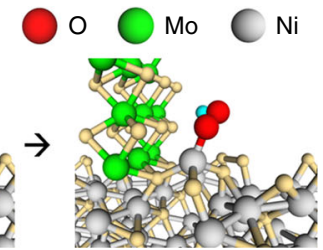

NiMoO $/$ NiMoS
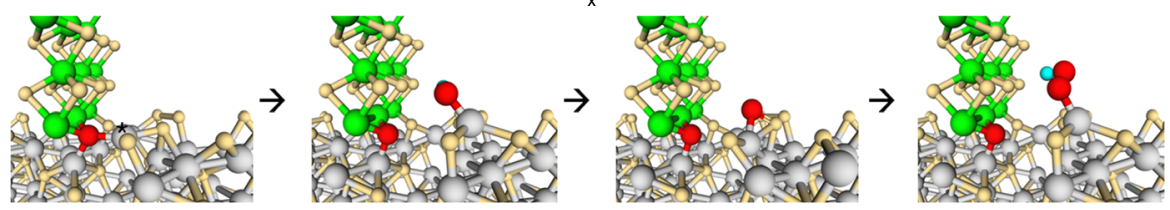

C

$\mathrm{Ni}_{3} \mathrm{~S}_{2} / \mathrm{MoS}_{2}$

d

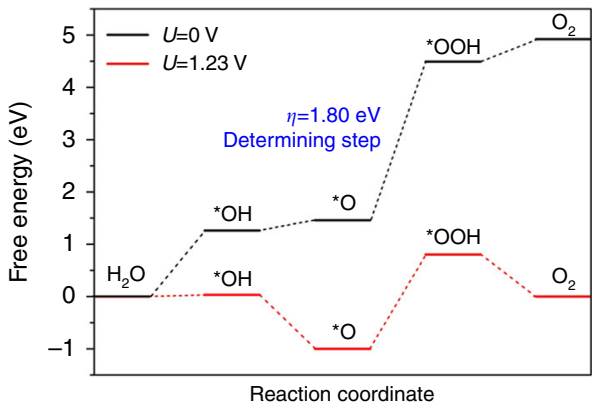

d $\mathrm{NiMoO}_{x} / \mathrm{NiMoS}$

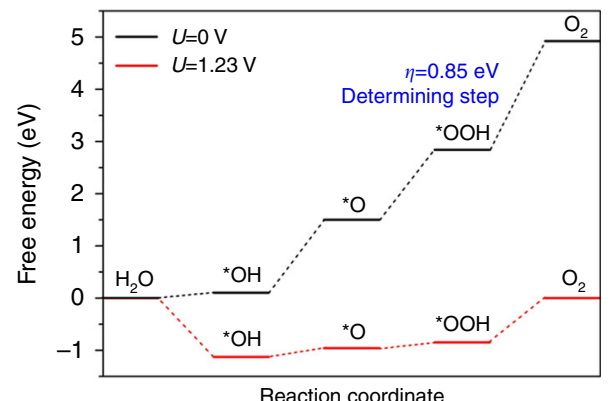

Fig. 8 Origin of HER/OER activities on $\mathrm{NiMoO}_{\mathbf{x}} / \mathrm{NiMoS}$ a Chemisorption models and corresponding Gibbs free energy of $\mathrm{H}$ on the interface of $\mathrm{Ni}_{3} \mathrm{~S}_{2} /$ $\mathrm{MoS}_{2}$ and $\mathrm{NiMoO}_{x} / \mathrm{NiMoS}$, on the surface of $\mathrm{NiO}_{x} / \mathrm{Ni}_{3} \mathrm{~S}_{2}(\mathrm{~S})$ and on the edge of $\mathrm{MoO}_{x} / \mathrm{MoS}_{2}(\mathrm{Mo})$. $\mathbf{b} \mathrm{OH}, \mathrm{O}$, and OOH intermediates adsorption configurations for OER on the interface of (top) $\mathrm{Ni}_{3} \mathrm{~S}_{2} / \mathrm{MoS}_{2}$ and (bottom) $\mathrm{NiMoO}$ / $/ \mathrm{NiMoS}$. $\mathbf{c}$, $\mathbf{d}$ The free energy diagrams for OER on the interface of $\mathbf{c}$ $\mathrm{Ni}_{3} \mathrm{~S}_{2} / \mathrm{MoS}_{2}$ and (d) $\mathrm{NiMoO}_{x} / \mathrm{NiMoS}$ heterostructures. Cyan, yellow, red, green, and gray balls, respectively, represents $\mathrm{H}, \mathrm{S}, \mathrm{O}, \mathrm{Mo}$, and $\mathrm{Ni}$ atoms.

array as a typical catalyst, offering a prospective solution of hierarchical electrocatalysts for practical water splitting applications.

\section{Discussion}

In summary, hierarchical transition bimetal oxides/sulfides array was fabricated by oxidation/hydrogenation-induced surface reconfiguration strategy by use of NiMoS architectures as the precursor, interacting two-dimensional $\mathrm{MoO}_{x} / \mathrm{MoS}_{2}$ nanosheets attached to one-dimensional $\mathrm{NiO}_{x} / \mathrm{Ni}_{3} \mathrm{~S}_{2}$ nanorods array. To optimize the electrocatalytic performance, the influence of oxygen plasma power and hydrogenation temperature upon HER and OER performance of $\mathrm{NiMoO}_{x} / \mathrm{NiMoS}$ array was explored, confirming the best plasma power of $100 \mathrm{~W}$ and appropriate thermal treatment temperature at $400^{\circ} \mathrm{C}$. Benefiting from heterostructure engineering, as-synthesized $\mathrm{NiMoO}_{x} / \mathrm{NiMoS}$ array presents the remarkable electrocatalytic performance, achieving low overpotentials of $38,89,174$, and $236 \mathrm{mV}$ for HER and 186, 225, 278, and $334 \mathrm{mV}$ for OER at $10,100,500$ and $1000 \mathrm{~mA} \mathrm{~cm}^{-2}$, even surviving at large current density of 100 and $500 \mathrm{~mA} \mathrm{~cm}^{-2}$ with long-term stability. The extraordinarily enhanced electrocatalytic performance of transition bimetal oxides/sulfides heterostructure array as the typical model is ascribed to not only the simultaneous modulation of component and geometric structure, but also the systematic optimization of charge transfer, abundant electrocatalytic active sites and exceptionally synergistic effect of heterostructure interfaces. Density functional theory calculations reveal that the coupling interface between $\mathrm{NiMoO}_{x}$ and NiMoS optimizes adsorption energies and accelerates water splitting kinetics, thus promoting the catalytic performance. Especially, the assembled two-electrode cell by use of $\mathrm{NiMoO}_{x} / \mathrm{NiMoS}$ array delivers the industrially required current densities of 500 and $1000 \mathrm{~mA} \mathrm{~cm}^{-2}$ at record low cell voltages of 1.60 and $1.66 \mathrm{~V}$, along with excellent durability, outperforming most of transition metal-based bifunctional electrocatalysts reported to date. Given hierarchical transition heterostructures array as typical model, this work could open up the avenues to the development of excellent electrocatalysts by engineering active sites for large-scale energy conversion applications.

\section{Methods}

Materials. Ni foam was purchased from Suzhou Jiashide Metal Foam Co. Ltd. Ni $\left(\mathrm{NO}_{3}\right)_{2} \cdot 6 \mathrm{H}_{2} \mathrm{O},\left(\mathrm{NH}_{4}\right) \mathrm{Mo}_{7} \mathrm{O}_{24} \cdot 4 \mathrm{H}_{2} \mathrm{O}$, thiourea and $\mathrm{KOH}$ was purchased from 
Aladdin. Pt/C (20 wt\% Pt on Vulcan XC-72R) and Nafion (5 wt\%) were purchased from Sigma-Aldrich. All chemicals were used as received without further purification. The water used throughout all experiments was purified through a Millipore system.

Fabrication of $\mathrm{NiMoO}_{\mathbf{x}} / \mathrm{NiMoS}$ heterostructure array. $0.07 \mathrm{M} \mathrm{Ni}\left(\mathrm{NO}_{3}\right)_{2} \cdot 6 \mathrm{H}_{2} \mathrm{O}$, $0.01 \mathrm{M}\left(\mathrm{NH}_{4}\right) \mathrm{Mo}_{7} \mathrm{O}_{24} \cdot 4 \mathrm{H}_{2} \mathrm{O}$ and $0.30 \mathrm{M}$ thiourea were dissolved into $15 \mathrm{~mL}$ deionized water and stirred for $10 \mathrm{~min}$ under room temperature. Then the solution was transferred to a $25 \mathrm{~mL}$ Teflon-lined steel autoclave with nickel foam. After hydrothermal reaction at $200^{\circ} \mathrm{C}$ for $24 \mathrm{~h}$, NiMoS precursor was obtained through washing with deionized water and then dried in an oven at $60^{\circ} \mathrm{C}$. As-obtained NiMoS precursors were irradiated by RF plasma under an oxygen flow (RF power, $50 \sim 150 \mathrm{~W}$ ) for the oxidation treatment. Afterward the arrays were annealed up to $300-500{ }^{\circ} \mathrm{C}$ in $\mathrm{H}_{2} / \mathrm{Ar}(0.05 / 0.95)$ for the typical hydrogenation regulation, thus resulting into the synthesis of $\mathrm{NiMoO}_{\mathrm{x}} / \mathrm{NiMoS}$ heterostructure array by oxidation/ hydrogenation-induced surface reconfiguration strategy. In comparison, asobtained $\mathrm{NiO}_{\mathrm{x}} / \mathrm{Ni}_{3} \mathrm{~S}_{2}$ and $\mathrm{MoO}_{\mathrm{x}} / \mathrm{MoS}_{2}$ heterostructure arrays were synthesized in parallel by the same procedure as that of $\mathrm{NiMoO}_{\mathrm{x}} / \mathrm{NiMoS}$ array expect for in absence of $\left(\mathrm{NH}_{4}\right) \mathrm{Mo}_{7} \mathrm{O}_{24} \cdot 4 \mathrm{H}_{2} \mathrm{O}$ or $\mathrm{Ni}\left(\mathrm{NO}_{3}\right)_{2} \cdot 6 \mathrm{H}_{2} \mathrm{O}$ in hydrothermal reaction.

Structural characterization. Powder XRD patterns of the products were tested with X-ray diffractometer (Japan Rigaku Rotaflex) by $\mathrm{Cu} \mathrm{K}_{\alpha}$ radiation $(\lambda=1.5418$ $\mathrm{nm}, 40 \mathrm{kV}, 40 \mathrm{~mA}$ ) at room temperature. SEM images of the products were captured by a field-emission scanning electron microscope (SEM, FEI Nova Nano SEM 450). TEM images of the products were performed on transmission electron microscopy (TEM, FEI TF30). The chemical states of the samples were determined by XPS in a Thermo VG ESCALAB250 surface analysis system. The shift of binding energy due to relative surface charging was corrected using the $\mathrm{C} 1 \mathrm{~s}$ level at $284.6 \mathrm{eV}$ as an internal standard.

Electrochemical measurements. The electrocatalytic HER and OER performance of different electrocatalysts $\left(1 \mathrm{~cm}^{2}\right)$ were evaluated using a typical three-electrode system in $\mathrm{N}_{2}$ and $\mathrm{O}_{2}$-saturated $1 \mathrm{M} \mathrm{KOH}$ electrolyte, respectively. All polarization curves at $1 \mathrm{mV} \mathrm{s}^{-1}$ were corrected with iR compensation. The mass loading of NiMoS-based electrocatalysts was tested according to the mass difference. Commercial $\mathrm{IrO}_{2}$ or $20 \mathrm{wt} \% \mathrm{Pt} / \mathrm{C}$ was dispersed in ethanol solution with Nafion and then the ink was dropped by a micropipettor on $\mathrm{Ni}$ foam. The EIS tests were measured by AC impedance spectroscopy at the frequency ranges $10^{6}$ to $0.1 \mathrm{~Hz}$. According to the Nernst equation $\left(E_{\mathrm{RHE}}=E_{\mathrm{Hg} / \mathrm{HgO}}+0.059 \mathrm{pH}+0.098\right)$, where $E_{\mathrm{RHE}}$ was the potential vs. a reversible hydrogen potential, $E_{\mathrm{Hg} / \mathrm{HgO}}$ was the potential vs. $\mathrm{Hg} / \mathrm{HgO}$ electrode, and $\mathrm{pH}$ was the $\mathrm{pH}$ value of electrolyte. To determination of Faradaic efficiency, the Faradaic efficiency of HER or OER catalyst is defined as the ratio of the amount of experimentally determined hydrogen or oxygen to that of the theoretically expected hydrogen or oxygen from the HER or OER reaction in $1 \mathrm{M} \mathrm{KOH}$ aqueous solution by use of an online gas chromatography system (GC, Techcomp GC 7890 T, Ar carrier gas, Thermo Conductivity Detector). As for the theoretical value, we assumed that $100 \%$ current efficiency during the reaction, which means only the HER or OER process was occurring at the working electrode. The theoretically expected amount of hydrogen or oxygen was then calculated by applying the Faraday law, which states that the passage of 96485.4 C causes 1 equivalent of reaction.

First-principle calculations. Density functional theory calculations were carried out by the Vienna ab initio simulation package (VASP), using the planewave basis with an energy cutoff of $400 \mathrm{eV}$, the projector augmented wave pseudopotentials, and the generalized gradient approximation parameterized by Perdew, Burke, and Ernzerhof (GGA-PBE) for exchange-correlation functional ${ }^{73}$. The Brillouin zones of the supercells were sampled by $4 \times 4 \times 1$ uniform $\mathrm{k}$ point mesh. With fixed cell parameters, the model structures were fully optimized using the convergence criteria of $10^{-5} \mathrm{eV}$ for the electronic energy and $10^{-2} \mathrm{eV} / \AA$ for the forces on each atom. The supercells dimension in $\mathrm{x}$ and $\mathrm{y}$ was $11.598 \AA$ and $12.243 \AA$, respectively. The vacuum region in the $\mathrm{z}$ direction was adopted large than $15 \AA$ so that the spurious interactions of neighboring models are negligible. Then $\mathrm{O}$ atom was used to replace the $\mathrm{S}$ atom on the edge of $\mathrm{MoS}_{2}$ and the surface of $\mathrm{Ni}_{3} \mathrm{~S}_{2}$ and the interface of $\mathrm{MoS}_{2}$ and $\mathrm{Ni}_{3} \mathrm{~S}_{2}$, respectively ${ }^{74}$. To simulate the edge, the surface and interface incorporate with the oxides. Both spin-polarized and spin-unpolarized computations were performed. The computational results show that both NiMoS and $\mathrm{NiMoO}_{\mathrm{x}} / \mathrm{NiMoS}$ are magnetic. In addition, we applied the DFT-D3 (BJ) method to evaluate the van der Waals (vdW) effect in all calculations.

The Gibbs free energy of the intermediates for HER and OER process, that is, $\mathrm{H}, \mathrm{OH}, \mathrm{O}$, and $\mathrm{OOH}$, can be calculated as ${ }^{75,76}$

$$
\Delta G=E_{\text {ads }}+\Delta E_{\mathrm{ZPE}}-T \Delta S
$$

where $E_{\mathrm{ads}}$ is the adsorption energy of intermediate, $\Delta E_{\mathrm{ZPE}}$ is the zero point energy difference between the adsorption state and gas state, $T$ is the temperature, and $\Delta S$ is the entropy various between the adsorption and gas phase. For adsorbates, $E_{\mathrm{ZPE}}$ and $S$ are obtained from vibrational frequencies calculations with harmonic approximation and contributions from the slabs are neglected, whereas for molecules these values are taken from NIST-JANAF thermochemical Tables ${ }^{77}$. The contributions are listed (Supplementary Table 8). Usually, the vibration entropy of hydrogen adsorption on the substrate is small, the entropy of hydrogen adsorption is $\Delta \mathrm{S} \approx-1 / 2 S^{\circ}$, where $S^{0}$ is the entropy of $\mathrm{H}_{2}$ in the gas phase at the standard conditions. The corrected for free energy equation was defined by

$$
\Delta G=E_{\text {ads }}+0.24 \mathrm{eV}
$$

The intermediates adsorption energy $E_{\text {ads }}$ for ${ }^{*} \mathrm{H},{ }^{*} \mathrm{OH},{ }^{*} \mathrm{O}$, and ${ }^{*} \mathrm{OOH}$ can be used as DFT ground state energy calculated as

$$
\begin{aligned}
& \Delta E{ }^{*} \mathrm{H}=E\left({ }^{*} \mathrm{H}\right)-E\left({ }^{*}\right)-1 / 2 E\left(\mathrm{H}_{2}\right) \\
& \Delta E{ }^{*} \mathrm{OOH} \\
& \Delta E{ }^{*} \mathrm{O}=E\left({ }^{*} \mathrm{OOH}\right)-E\left({ }^{*}\right)-\left(2 E_{\mathrm{H}_{2} \mathrm{O}}-3 / 2 E_{\mathrm{H}_{2}}\right) \\
& \left.\Delta E{ }^{*}\right)-\left(E_{\mathrm{H}_{2} \mathrm{O}}-E_{\mathrm{H}_{2}}\right) \\
& =E\left({ }^{*} \mathrm{OH}\right)-E\left({ }^{*}\right)-\left(E_{\mathrm{H}_{2} \mathrm{O}}-1 / 2 E_{\mathrm{H}_{2}}\right)
\end{aligned}
$$
steps:

$$
\begin{array}{cc}
{ }^{*}+\mathrm{OH}^{-} \rightarrow \mathrm{OH}^{*}+\mathrm{e}^{-} & \Delta G_{1} \\
\mathrm{OH}^{*}+\mathrm{OH}^{-} \rightarrow{ }^{*} \mathrm{O}+\mathrm{H}_{2} \mathrm{O}+\mathrm{e}^{-} & \Delta G_{2} \\
{ }^{*} \mathrm{O}+\mathrm{OH}^{-} \rightarrow \mathrm{OOH}^{*}+\mathrm{e}^{-} & \Delta G_{3} \\
\mathrm{OOH}^{*}+\mathrm{OH}^{-} \rightarrow \mathrm{O}_{2}+\mathrm{H}_{2} \mathrm{O}+\mathrm{e}^{-}+{ }^{*} & \Delta G_{4}
\end{array}
$$

where ${ }^{*}$ denotes adsorption active site on the substrate.

$$
\begin{gathered}
\Delta G_{1}=\Delta G^{*^{*} \mathrm{H}} \\
\Delta G_{2}=\Delta G^{*} \mathrm{O}-\Delta G^{*} \mathrm{OH} \\
\Delta G_{3}=\Delta G^{*} \mathrm{OOH}-\Delta G^{*} \mathrm{O} \\
\Delta G_{4}=4.92-\Delta G^{*} \mathrm{OOH}
\end{gathered}
$$

The overpotential $\eta$ is defined as

$$
\eta=\max \left\{\Delta G_{1}, \Delta G_{2}, \Delta G_{3}, \Delta G_{4}\right\}-1.23 \mathrm{eV}
$$

\section{Data availability}

The data that support the findings of this work are available from the corresponding author upon reasonable request.

Received: 7 April 2020; Accepted: 1 October 2020; Published online: 29 October 2020

\section{References}

1. Jiao, Y. et al. Design of electrocatalysts for oxygen- and hydrogen-involving energy conversion reactions. Chem. Soc. Rev. 44, 2060-2086 (2015).

2. Xia, Z. \& Guo, S. Strain engineering of metal-based nanomaterials for energy electrocatalysis. Chem. Soc. Rev. 48, 3265-3278 (2019).

3. Wei, C. et al. Approaches for measuring the surface areas of metal oxide electrocatalysts for determining their intrinsic electrocatalytic activity. Chem. Soc. Rev. 48, 2518-2534 (2019).

4. Zou, X. \& Zhang, Y. Noble metal-free hydrogen evolution catalysts for water splitting. Chem. Soc. Rev. 44, 5148-5180 (2015).

5. Pi, Y. et al. Trimetallic oxyhydroxide coralloids for efficient oxygen evolution electrocatalysis. Angew. Chem. Int. Ed. 56, 4502-4506 (2017).

6. Huang, L. et al. Zirconium-regulation-induced bifunctionality in 3D cobaltiron oxide nanosheets for overall water splitting. Adv. Mater. 31, 1901439 (2019).

7. Hao, $\mathrm{S}$. et al. NiCoMo hydroxide nanosheet arrays synthesized via chloride corrosion for overall water splitting. ACS Energy Lett. 4, 952-959 (2019).

8. Hou, J. et al. Active sites intercalated ultrathin carbon sheath on nanowire arrays as integrated core-shell architecture: highly efficient and durable electrocatalysts for overall water splitting. Small 13, 1702018 (2017).

9. Yang, L. et al. Efficient oxygen evolution electrocatalysis in acid by a perovskite with face-sharing $\mathrm{IrO}_{6}$ octahedral dimmers. Nat. Commun. 9, 5236 (2018).

10. Chen, H. et al. Promoting subordinate, efficient ruthenium sites with interstitial silicon for Pt-Like electrocatalytic activity. Angew. Chem. Int. Ed. 58, 11409 (2019). 
11. Liang, X. et al. Activating inert, nonprecious perovskites with iridium dopants for efficient oxygen evolution reaction under acidic conditions. Angew. Chem. Int. Ed. 58, 17631 (2019).

12. Huang, L. B. et al. Self-limited on-site conversion of $\mathrm{MoO}_{3}$ nanodots into vertically aligned ultrasmall monolayer $\mathrm{MoS}_{2}$ for efficient hydrogen evolution. Adv. Energy Mater. 8, 1800734 (2018).

13. Zhang, J. et al. Efficient hydrogen production on $\mathrm{MoNi}_{4}$ electrocatalysts with fast water dissociation kinetics. Nat. Commun. 8, 15437 (2017).

14. Chen, Y. Y. et al. Self-templated fabrication of $\mathrm{MoNi}_{4} / \mathrm{MoO}_{3-\mathrm{x}}$ nanorod arrays with dual active components for highly efficient hydrogen evolution. $A d v$. Mater. 29, 1703311 (2017).

15. An, L. et al. Epitaxial heterogeneous interfaces on $\mathrm{N}-\mathrm{NiMoO} / \mathrm{NiS}_{2}$ nanowires/ nanosheets to boost hydrogen and oxygen production for overall water splitting. Adv. Funct. Mater. 29, 1805298 (2019).

16. Zhang, $\mathrm{X}$. et al. $\mathrm{Co}_{3} \mathrm{O}_{4} / \mathrm{Fe}_{0.33} \mathrm{Co}_{0.66} \mathrm{P}$ interface nanowire for enhancing water oxidation catalysis at high current density. Adv. Mater. 30, 1803551 (2018)

17. Liu, $\mathrm{T}$. et al. Interfacial electron transfer of $\mathrm{Ni}_{2} \mathrm{P}-\mathrm{NiP}_{2}$ polymorphs inducing enhanced electrochemical properties. Adv. Mater. 30, 1803590 (2018).

18. Niu, S. et al. Autogenous growth of hierarchical $\mathrm{NiFe}(\mathrm{OH})_{\mathrm{x}} / \mathrm{FeS}$ nanosheeton-microsheet arrays for synergistically enhanced high-output water oxidation. Adv. Funct. Mater. 29, 1902180 (2019).

19. Peng, Y. W. et al. Polyoxometalate-derived ultrasmall $\mathrm{Pt}_{2} \mathrm{~W} / \mathrm{WO}_{3}$ heterostructure outperforms platinum for large-current-density $\mathrm{H}_{2}$ evolution. Adv. Energy Mater. 9, 1900597 (2019).

20. Hou, J. et al. Promoting active sites in core-shell nanowire array as MottSchottky electrocatalysts for efficient and stable overall water splitting. $A d v$. Funct. Mater. 28, 1704447 (2018).

21. Feng, J. X. et al. $\mathrm{Co}(\mathrm{OH})_{2} @ P A N I$ hybrid nanosheets with 3D networks as high-performance electrocatalysts for hydrogen evolution reaction. Adv. Mater. 27, 7051-7057 (2015)

22. Feng, J. X. et al. FeOOH/Co/FeOOH hybrid nanotube arrays as highperformance electrocatalysts for the oxygen evolution reaction. Angew. Chem. Int. Ed. 55, 3694-3698 (2016).

23. Lei, C. et al. Efficient alkaline hydrogen evolution on atomically dispersed $\mathrm{Ni}-\mathrm{N}_{\mathrm{x}}$ species anchored porous carbon with embedded $\mathrm{Ni}$ nanoparticles by accelerating water dissociation kinetics. Energy Environ. Sci. 12, 149-156 (2019).

24. Yan, H. et al. Anion-modulated HER and OER activities of 3D Ni-V-based interstitial compound heterojunctions for high-efficiency and stable overall water splitting. Adv. Mater. 31, 1901174 (2019).

25. Hou, J. et al. Electrical behavior and electron transfer modulation of nickelcopper nanoalloys confined in nickel-copper nitrides nanowires array encapsulated in nitrogen-doped carbon framework as robust bifunctional electrocatalyst for overall water splitting. Adv. Funct. Mater. 28, 1803278 (2018).

26. Yoon, T. \& Kim, K. S. One-step synthesis of CoS-Doped $\beta$-Co $(\mathrm{OH})_{2} @$ amorphous $\mathrm{MoS}_{2+\mathrm{x}}$ hybrid catalyst grown on nickel foam for high performance electrochemical overall water splitting. Adv. Funct. Mater. 26, 7386-7393 (2016).

27. $\mathrm{Wu}, \mathrm{Y}$. et al. Coupling interface constructions of $\mathrm{MoS}_{2} / \mathrm{Fe}_{5} \mathrm{Ni}_{4} \mathrm{~S}_{8}$ heterostructures for efficient electrochemical water splitting. Adv. Mater. 30, 1803151 (2018).

28. Zhang, J. et al. Interface engineering of $\mathrm{MoS}_{2} / \mathrm{Ni}_{3} \mathrm{~S}_{2}$ heterostructures for highly enhanced electrochemical overall-water-splitting activity. Angew. Chem. Int. Ed. 55, 6702-6707 (2016).

29. An, T. et al. Interlaced $\mathrm{NiS}_{2}-\mathrm{MoS}_{2}$ nanoflake-nanowires as efficient hydrogen evolution electrocatalysts in basic solutions. J. Mater. Chem. A 4, 13439-13443 (2016).

30. Yang, Y. et al. Hierarchical nanoassembly of $\mathrm{MoS}_{2} / \mathrm{Co}_{9} \mathrm{~S}_{8} / \mathrm{Ni}_{3} \mathrm{~S}_{2} / \mathrm{Ni}$ as a highly efficient electrocatalyst for overall water splitting in a wide $\mathrm{pH}$ range. J. Am. Chem. Soc. 141, 10417-10430 (2019).

31. Li, H. et al. Systematic design of superaerophobic nanotube-array electrode comprised of transition-metal sulfides for overall water splitting. Nat. Commun. 9, 2452 (2018)

32. Wang, X. et al. Single-atom vacancy defect to trigger high-efficiency hydrogen evolution of $\mathrm{MoS}_{2}$. J. Am. Chem. Soc. 142, 4298 (2020).

33. Luo, Z. et al. Reactant friendly hydrogen evolution interface based on dianionic $\mathrm{MoS}_{2}$ surface. Nat. Commun. 11, 1116 (2020).

34. He, W. et al. Fluorine-anion-modulated electron structure of nickel sulfide nanosheet arrays for alkaline hydrogen evolution. ACS Energy Lett. 4, 2905 (2019).

35. Feng, L. et al. High-index faceted $\mathrm{Ni}_{3} \mathrm{~S}_{2}$ nanosheet arrays as highly active and ultrastable electrocatalysts for water splitting. J. Am. Chem. Soc. 137, 14023 (2015).

36. Zhu, H. et al. When cubic cobalt sulfide meets layered molybdenum disulfide: A core-shell system toward synergetic electrocatalytic water splitting. Adv. Mater. 27, 4752 (2015).
37. Feng, J. et al. Efficient hydrogen evolution on $\mathrm{Cu}$ nanodots-decorated $\mathrm{Ni}_{3} \mathrm{~S}_{2}$ nanotubes by optimizing atomic hydrogen adsorption and desorption. J. Am. Chem. Soc. 140, 610 (2018).

38. Chen, D. et al. Preferential cation vacancies in perovskite hydroxide for the oxygen evolution reaction. Angew. Chem. Int. Ed. 57, 8691-8696 (2018).

39. Xiao, Z. et al. Filling the oxygen vacancies in $\mathrm{Co}_{3} \mathrm{O}_{4}$ with phosphorus: an ultra-efficient electrocatalyst for overall water splitting. Energy Environ. Sci. 10, 2563-2569 (2017).

40. Wang, Y. et al. 3D carbon electrocatalysts in situ constructed by defect-rich nanosheets and polyhedrons from $\mathrm{NaCl}$-sealed zeolitic imidazolate frameworks. Adv. Funct. Mater. 28, 1705356 (2018).

41. Smith, R. et al. Photochemical route for accessing amorphous metal oxide materials for water oxidation catalysis. Science 340, 60-63 (2013).

42. Hou, J. et al. Vertically aligned oxygenated- $\mathrm{CoS}_{2}-\mathrm{MoS}_{2}$ heteronanosheet architecture from polyoxometalate for efficient and stable overall water splitting. ACS Catal. 8, 4612-4621 (2018).

43. Meng, L. et al. Simultaneous manipulation of O-doping and metal vacancy in atomically thin $\mathrm{Zn}_{10} \mathrm{In}_{16} \mathrm{~S}_{34}$ nanosheet arrays toward improved photoelectrochemical performance. Angew. Chem. Int. Ed. 57, 16882-16887 (2018).

44. Li, H. et al. Activating and optimizing $\mathrm{MoS}_{2}$ basal planes for hydrogen evolution through the formation of strained sulphur vacancies. Nat. Mater. 15, 48 (2015).

45. Kibsgaard, J. \& Jaramillo, T. F. Molybdenum phosphosulfide: An active, acidStable, earth-abundant catalyst for the hydrogen evolution reaction. Angew. Chem. Int. Ed. 53, 14433 (2014).

46. Kibsgaard, J. et al. Designing an improved transition metal phosphide catalyst for hydrogen evolution using experimental and theoretical trends. Energy Environ. Sci. 8, 3022 (2015).

47. Han, X. et al. Ultrafine Pt nanoparticle-decorated pyrite-type $\mathrm{CoS}_{2}$ nanosheet arrays coated on carbon cloth as a bifunctional electrode for overall water splitting. Adv. Energy Mater. 8, 1800935 (2018)

48. Liu, Y. et al. Corrosion engineering towards efficient oxygen evolution electrodes with stable catalytic activity for over 6000 hours. Nat. Commun. 9 2609 (2018)

49. Hao, W. et al. Fabrication of practical catalytic electrodes using insulating and eco-friendly substrates for overall water splitting. Energy Environ. Sci. 13, 102-110 (2020)

50. Wang, D. et al. Atomic and electronic modulation of self-supported nickelvanadium layered double hydroxide to accelerate water splitting kinetics. Nat. Commun. 10, 3899 (2019).

51. Zhang, J. et al. Modulation of inverse spinel $\mathrm{Fe}_{3} \mathrm{O}_{4}$ by phosphorus doping as an industrially promising electrocatalyst for hydrogen evolution. Adv. Mater. 31, 1905107 (2019).

52. Zhu, C. et al. Fe-Ni-Mo nitride porous nanotubes for full water splitting and Zn-air batteries. Adv. Energy Mater. 8, 1802327 (2018).

53. Sun, Y. et al. Strong electronic interaction in dual-cation-incorporated $\mathrm{NiSe}_{2}$ nanosheets with lattice distortion for highly efficient overall water splitting. Adv. Mater. 30, 1802121 (2018).

54. Lin, J. et al. Defect-rich heterogeneous $\mathrm{MoS}_{2} / \mathrm{NiS}_{2}$ nanosheets electrocatalysts for efficient overall water splitting. Adv. Sci. 6, 1900246 (2019).

55. Zhai, Z. et al. Dimensional construction and morphological tuning of heterogeneous $\mathrm{MoS}_{2} / \mathrm{NiS}$ electrocatalysts for efficient overall water splitting. $J$. Mater. Chem. A 6, 9833-9838 (2018).

56. Wang, Z. et al. Phosphorus-doped $\mathrm{Co}_{3} \mathrm{O}_{4}$ nanowire array: a highly efficient bifunctional electrocatalyst for overall water splitting. ACS Catal. 8, 2236-2241 (2018)

57. $\mathrm{Li}, \mathrm{M}$. et al. Ni strongly coupled with $\mathrm{Mo}_{2} \mathrm{C}$ encapsulated in nitrogen-doped carbon nanofibers as robust bifunctional catalyst for overall water splitting. Adv. Energy Mater. 9, 1803185 (2019).

58. Li, S. et al. Co-Ni-based nanotubes/nanosheets as efficient water splitting electrocatalysts. Adv. Energy Mater. 6, 1501661 (2016).

59. Sivanantham, A., Ganesan, P. \& Shanmugam, S. Hierarchical $\mathrm{NiCo}_{2} \mathrm{~S}_{4}$ nanowire arrays supported on $\mathrm{Ni}$ foam: an efficient and durable bifunctional electrocatalyst for oxygen and hydrogen evolution reactions. Adv. Funct. Mater. 26, 4661-4672 (2016)

60. Liu, B. et al. Iron vacancies induced bifunctionality in ultrathin feroxyhyte nanosheets for overall water splitting. Adv. Mater. 30, 1803144 (2018).

61. Ledendecker, $\mathrm{M}$. et al. The synthesis of nanostructured $\mathrm{Ni}_{5} \mathrm{P}_{4}$ films and their use as a non-noble bifunctional electrocatalyst for full water splitting. Angew. Chem. Int. Ed. 54, 12361-12365 (2015).

62. Yan, X. et al. From water oxidation to reduction: transformation from $\mathrm{Ni}_{\mathrm{X}} \mathrm{Co}_{3}$ ${ }_{\mathrm{x}} \mathrm{O}_{4}$ nanowires to $\mathrm{NiCo} / \mathrm{NiCoO}_{\mathrm{x}}$ heterostructures. ACS Appl. Mater. Interfaces 8, 3208-3214 (2016).

63. Zhao, X. et al. Bifunctional electrocatalysts for overall water splitting from an iron/nickel-based bimetallic metal-organic framework/dicyandiamide composite. Angew. Chem. Int. Ed. 57, 8921-8926 (2018). 
64. Yang, Y. et al. Porous cobalt-based thin film as a bifunctional catalyst for hydrogen generation and oxygen generation. Adv. Mater. 27, 3175-3180 (2015).

65. Yu, L. et al. Non-noble metal-nitride based electrocatalysts for highperformance alkaline seawater electrolysis. Nat. Commun. 10, 5106 (2019).

66. Li, H. et al. Amorphous nickel-cobalt complexes hybridized with 1T-phase molybdenum disulfide via hydrazineinduced phase transformation for water splitting. Nat. Commun. 8, 15377 (2019).

67. Hui, L. Overall water splitting by graphdiyne-exfoliated and -sandwiched layered double-hydroxide nanosheet arrays. Nat. Commun. 9, 5309 (2018).

68. Wang, Q. et al. Coordination engineering of iridium nanocluster bifunctional electrocatalyst for highly efficient and $\mathrm{pH}$-universal overall water splitting. Nat. Commun. 11, 4246 (2020).

69. Shi, H. et al. Spontaneously separated intermetallic $\mathrm{Co}_{3} \mathrm{Mo}$ from nanoporous copper as versatile electrocatalysts for highly efficient water splitting. Nat. Commun. 11, 2940 (2020).

70. Yu, F. et al. High-performance bifunctional porous non-noble metal phosphide catalyst for overall water splitting. Nat. Commun. 9, 2551 (2018).

71. Nørskov, J. K. et al. Trends in the exchange current for hydrogen evolution. J. Electrochem. Soc. 152, J23-J26 (2005).

72. Koper, M. T. M. Theory of multiple proton-electron transfer reactions and its implications for electrocatalysis. Chem. Sci. 4, 2710-2723 (2013).

73. Perdew, J. P., Burke, K. \& Ernzerhof, M. Generalized gradient approximation made simple. Phys. Rev. Lett. 77, 3865 (1996).

74. Peng, L. et al. Rationally design of monometallic $\mathrm{NiO}-\mathrm{Ni}_{3} \mathrm{~S}_{2} / \mathrm{NF}$ heteronanosheets as bifunctional electrocatalysts for overall water splitting. $J$. Catal. 369, 345-351 (2019).

75. Zhang, B. et al. Integrating $\mathrm{Rh}$ species with NiFe-layered double hydroxide for overall water splitting. Nano Lett. 20, 136-144 (2020).

76. Rossmeisl, J., Logadottir, A. \& Nørskov, J. K. Electrolysis of water on (oxidized) metal surfaces. Chem. Phys. 319, 178-184 (2005).

77. NIST-JANAF Thermochemical Tables. https://janaf.nist.gov/.

\section{Acknowledgements}

This work was supported by National Natural Science Foundation of China (Nos. 21972015, 51672034), Young top talents project of Liaoning Province (No. XLYC1907147), Joint Research Fund Liaoning-Shenyang National Laboratory for Materials Science (No. 2019JH3/30100003), the Fundamental Research Funds for the Central Universities (No. DUT20TD06), the Swedish Research Council, and the K\&A Wallenberg Foundation.

\section{Author contributions}

J.H. supervised this study. J.H., P.Z., and Y.W. conceived the idea. P.Z. and Y.W. planned and carried out the experiments, collected, and analyzed the experimental data. S.C. performed SEM and TEM characterizations. Y.Z. and J.G. conducted theoretical calculations. P.Z., Y.W., and J.H. wrote the paper. All the authors have discussed the results and wrote the paper together.

\section{Competing interests}

The authors declare no competing interests.

\section{Additional information}

Supplementary information is available for this paper at https://doi.org/10.1038/s41467020-19214-w.

Correspondence and requests for materials should be addressed to J.H.

Peer review information Nature Communications thanks Fangyi Cheng, Batyr Garlyyev, and other, anonymous, reviewers for their contributions to the peer review of this work. Peer review reports are available.

Reprints and permission information is available at http://www.nature.com/reprints

Publisher's note Springer Nature remains neutral with regard to jurisdictional claims in published maps and institutional affiliations.

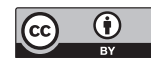

Open Access This article is licensed under a Creative Commons Attribution 4.0 International License, which permits use, sharing, adaptation, distribution and reproduction in any medium or format, as long as you give appropriate credit to the original author(s) and the source, provide a link to the Creative Commons license, and indicate if changes were made. The images or other third party material in this article are included in the article's Creative Commons license, unless indicated otherwise in a credit line to the material. If material is not included in the article's Creative Commons license and your intended use is not permitted by statutory regulation or exceeds the permitted use, you will need to obtain permission directly from the copyright holder. To view a copy of this license, visit http://creativecommons.org/ licenses/by/4.0/.

(C) The Author(s) 2020 